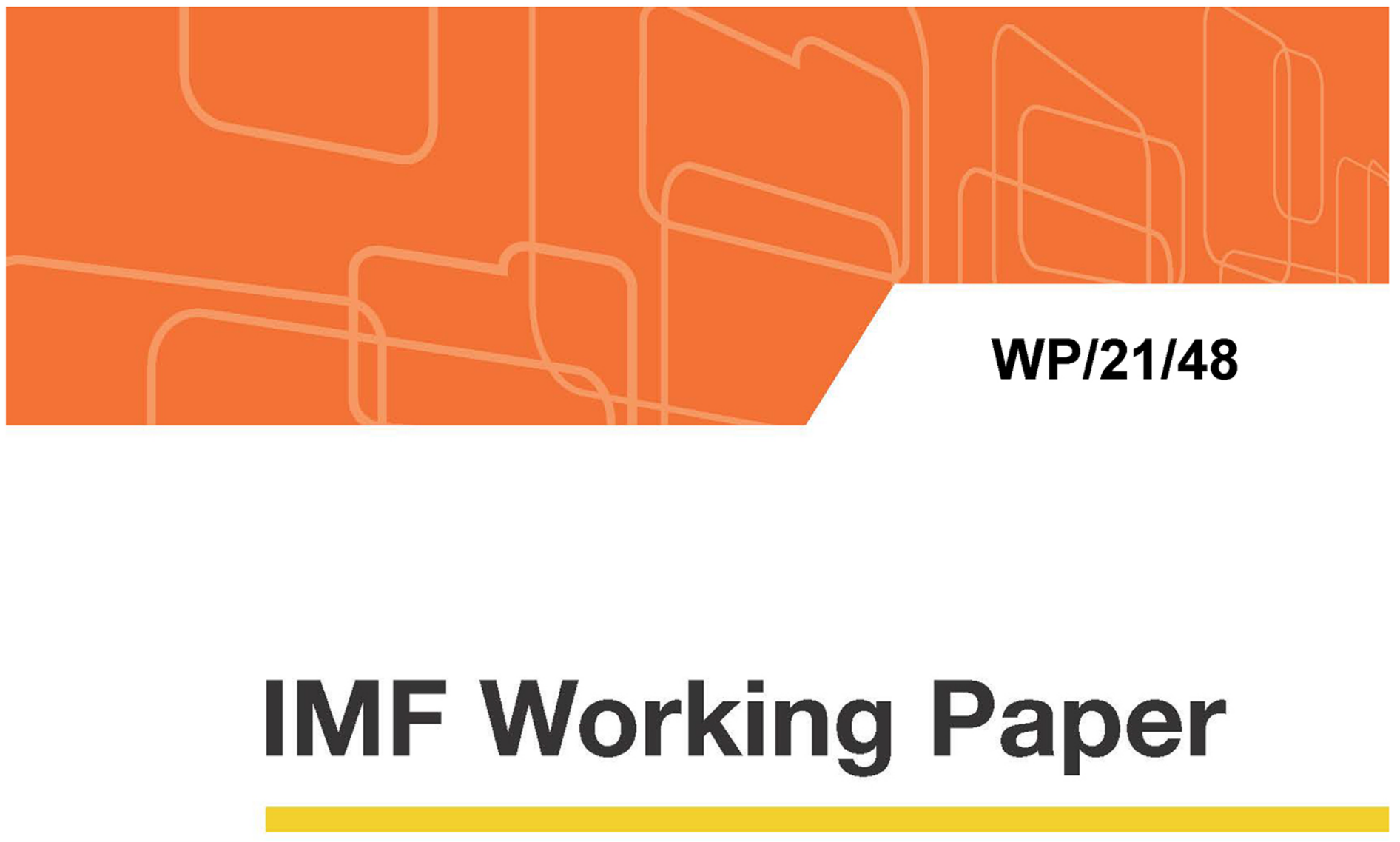

\title{
What Drives Innovation? Lessons from COVID-19 R\&D
}

by Ruchir Agarwal and Patrick Gaule

IMF Working Papers describe research in progress by the author(s) and are published to elicit comments and to encourage debate. The views expressed in IMF Working Papers are those of the author(s) and do not necessarily represent the views of the IMF, its Executive Board, or IMF management.

$$
\text { I N T E R N A T I O N A L M O N E T A R Y F U N D }
$$




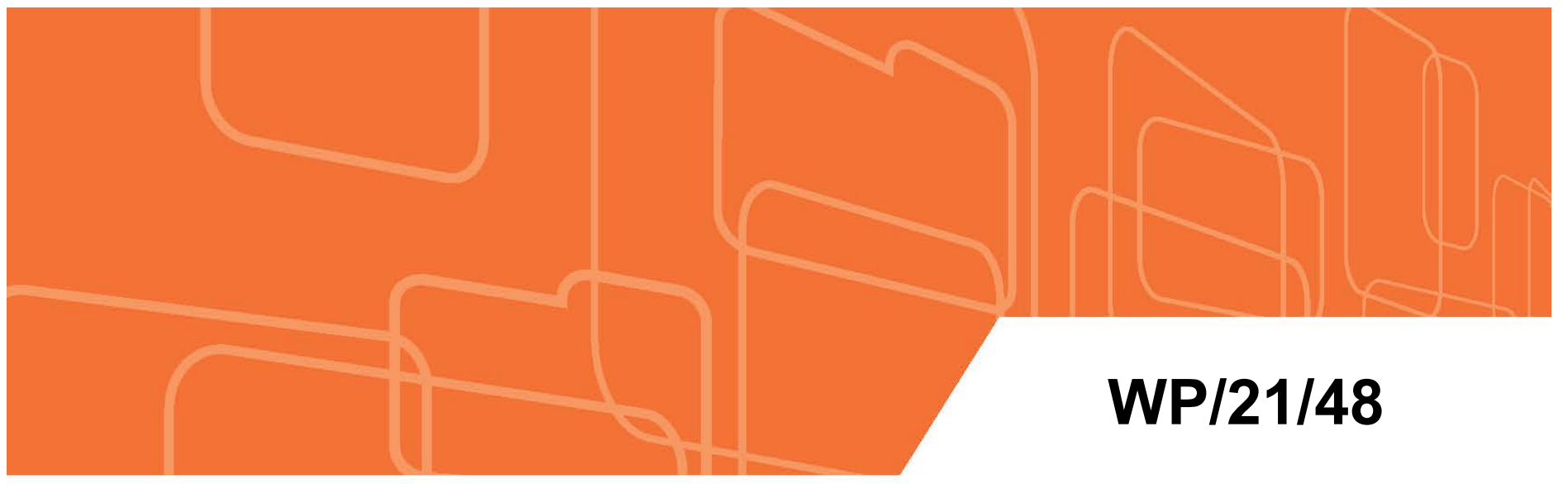

\section{IMF Working Paper}

\section{What Drives Innovation? Lessons from COVID-19 R\&D}

by Ruchir Agarwal and Patrick Gaule

IMF Working Papers describe research in progress by the author(s) and are published to elicit comments and to encourage debate. The views expressed in IMF Working Papers are those of the author(s) and do not necessarily represent the views of the IMF, its Executive Board, or IMF management.

$$
\text { I N T E R N A T I O N A L M O N E T A R Y F U N D }
$$


(C) 2021 International Monetary Fund

$\mathrm{WP} / 21 / 48$

\title{
IMF Working Paper
}

Asia and Pacific Department

What Drives Innovation? Lessons from COVID-19 R\&D

Prepared by Ruchir Agarwal, Patrick Gaule

Authorized for distribution by Alfred Schipke

February 2021

\section{IMF Working Papers describe research in progress by the author(s) and are published to elicit comments and to encourage debate. The views expressed in IMF Working Papers are those of the author(s) and do not necessarily represent the views of the IMF, its Executive Board, or IMF management.}

\begin{abstract}
To examine the drivers of innovation, this paper studies the global R\&D effort to fight the deadliest diseases and presents four results. We find: (1) global pharmaceutical R\&D activity-measured by clinical trials - typically follows the 'law of diminishing effort': i.e. the elasticity of R\&D effort with respect to market size is about $1 / 2$ in the cross-section of diseases; (2) the R\&D response to COVID-19 has been a major exception to this law, with the number of COVID-19 trials being 7 to 20 times greater than that implied by its market size; (3) the aggregate short-term elasticity of science and innovation can be very large, as demonstrated by aggregate flow of clinical trials increasing by $38 \%$ in 2020 , with limited crowding out of trials for non-COVID diseases; and (4) public institutions and government-led incentives were a key driver of the COVID-19 R\&D effort—with public research institutions accounting for 70 percent of all COVID-19 clinical trials globally and being 10 percentage points more likely to conduct a COVID-19 trial relative to private firms. Overall, while economists are naturally in favor of market size as a driving force for innovation (i.e."if the market size is sufficiently large then innovation will happen"), our work suggests that scaling up global innovation may require a broader perspective on the drivers of innovation-including early-stage incentives, non-monetary incentives, and public institutions.
\end{abstract}

JEL Classification Numbers:

Keywords: COVID-19, Innovation, Market Size, Pharmaceutical Industry

Author’s E-Mail Address: RAgarwal@imf.org., P.Gaule@bath.ac.uk 


\title{
What Drives Innovation? Lessons from COVID-19 R\&D
}

\author{
Ruchir Agarwal and Patrick Gaule*
}

February 3, 2021

\begin{abstract}
To examine the drivers of innovation, this paper studies the global R\&D effort to fight the deadliest diseases and presents four results. We find: (1) global pharmaceutical R\&D activity - measured by clinical trials - typically follows the 'law of diminishing effort': i.e. the elasticity of $R \& D$ effort with respect to market size is about $1 / 2$ in the cross-section of diseases; (2) the R\&D response to COVID-19 has been a major exception to this law, with the number of COVID-19 trials being 7 to 20 times greater than that implied by its market size; (3) the aggregate short-term elasticity of science and innovation can be very large, as demonstrated by aggregate flow of clinical trials increasing by $38 \%$ in 2020 , with limited crowding out of trials for non-COVID diseases; and (4) public institutions and government-led incentives were a key driver of the COVID-19 R\&D effort—with public research institutions accounting for 70 percent of all COVID-19 clinical trials globally and being 10 percentage points more likely to conduct a COVID-19 trial relative to private firms. Overall, while economists are naturally in favor of market size as a driving force for innovation (i.e. "if the market size is sufficiently large then innovation will happen"), our work suggests that scaling up global innovation may require a broader perspective on the drivers of innovation-including early-stage incentives, non-monetary incentives, and public institutions.
\end{abstract}

Keywords: COVID-19, Innovation, Market Size, Pharmaceutical Industry

\footnotetext{
*Agarwal: International Monetary Fund, RAgarwal@imf.org. Gaule: University of Bath, P.Gaule@ bath.ac.uk. Acknowledgements: We thank Pierre Azoulay, Dan Cao, Jeff Clemens, Annamaria Conti, Tom Cunningham, Ehsan Ebrahimy, Dominique Foray, Ina Ganguli, Stefano Giglio, Jonathan Gruber, Luigi Iovino, Miles Kimball, Nikolas Mittag, Morten Olsen, Ammon Salter, Rossella Salandra, Holger Spamann, and Heidi Williams. Further, as economists who study science, we are humbled by the ingenuity and tireless effort of scientists, health workers, regulators, industry participants and others who brought about an unprecedented scientific response to fight the COVID-19 pandemic. All errors are our own. The views expressed therein are those of the authors and do not necessarily represent the views of the IMF, its Executive Board, or IMF management.
} 


\section{Introduction}

The COVID-19 pandemic is one of the greatest challenges ever faced by modern medicine. When China publicly shared the genetic sequence of COVID-19 on January 12th, 2020, scientists quickly began working on vaccines, treatments, and diagnostics to fight SARS-CoV-2. However, the world was not hopeful for quick success. ${ }^{1}$ On the vaccine front, the fastest any vaccine had previously been developed was four years, for mumps in the 1960s, and thus even predictions of success by the summer of 2021 seemed highly optimistic (Ball 2021). Similarly, on the treatment front, limited progress had been made on the other known coronaviruses that cause disease in humans despite decades of research.

The scientific community responded with a massive R\&D effort to fight the COVID-19 pandemic. $^{2}$ By December 2020, several vaccine candidates had excellent results in large trials, with two vaccines (developed by Pfizer/BionTech and Moderna) receiving emergency use authorization in several countries. Similarly, on the treatment front, researchers had identified various treatments-e.g. dexamethasone, IL-6 blockers, monoclonal antibodies - that could bring a moderate reduction in mortality rates. ${ }^{3}$ While, major challenges remain in scaling up the production and distribution of vaccines and tackling the new virus strains, the pharmaceutical innovation response to COVID-19 has already turned out to be an unprecedented success in terms of product discovery and development.

The COVID-19 experience demonstrates that drug development can potentially proceed rapidly—without compromising on safety-when there is a global emergency and sufficient resources available for research and development (R\&D). This begs the question: what lessons can we draw from the innovation response to COVID-19 about the drivers of innovation, and how can it inform the global effort to scale up innovation to fight other deadly diseases? Shedding light on this question is the key focus of our paper.

The COVID-19 pandemic is a rare instance of a large discrete shift in global medical needs, and thus the market size for the pharmaceutical industry. This allows us to examine how the entire landscape of clinical trials altered in response to the COVID-19 shift. With that aim, we present four key results based on publicly available data on pharmaceutical clinical trials around the world. To set up the discussion of our results it is

\footnotetext{
${ }^{1}$ Begum et al. (2020) and Saif (2020) listed multiple bottlenecks in COVID-19 vaccine development, including the absence of animal models that could appropriately mimic the human COVID-19 infection. Pillaiyar, Meenakshisundaram, \& Manickam Abi (2020) noted that, based on historical experience, it could take more than 10 years for a new potent anti-COVID-19 anti-viral agent to be approved. Abi Younes et al (2020) suggested that COVID-19 R\&D effort might be hard to scale up in the short run due to scarcity of ideas or human capital.

${ }^{2}$ The closest historical equivalent is perhaps the Manhattan project, as noted by multiple observers (see e.g. Gross \& Sampat 2021). Also, over the medium term, the COVID-19 innovation response may end up boosting research progress in multiple areas, including for messenger RNA (mRNA) medicines that effectively instruct a patient's own cells to produce proteins to prevent, treat, or cure disease.

${ }^{3}$ Also, a drug called remdesivir was approved by the U.S. Federal Drug Administration (FDA) in October 2020, while some others were granted emergency use authorization.
} 
useful to consider the equation for optimal effort based on our extension of the classic model of innovation and market size developed by Acemoglu and Linn (2004). As per our model, the $\log \mathrm{R} \& \mathrm{D}$ effort $\ln z_{j}$ for disease $j$ is a function of non-monetary incentives $\eta$ and $\log$ market $\operatorname{size} \ln Y_{j}$. That is:

$$
\ln z_{j}=\text { Constant }+\eta+(1-\beta) \ln Y_{j}
$$

Our key findings are:

\#1. We estimate that the elasticity of $R \& D$ effort with respect to market size is about $1 / 2$ in the cross-section of diseases, i.e. $\beta \approx 0.5$. We establish this cross-sectional relationship between the market size of a disease (measured as the disease-level mortality risk at the national level weighted by national income levels) and R\&D effort (measured as new clinical trials), by matching data on world-wide clinical trials to 75 broad disease categories that have a non-negligible death burden. We estimate an elasticity strictly less than 1 (and around $1 / 2$ ) across all disease categories and also within sub-categories (such as cancer or infectious diseases) with the $R^{2}$ of the univariate regressions ranging from about 0.3 to 0.5 . Based on this strong empirical regularity we call this relationship "the law of diminishing effort."

\#2. We document that the R\&D response to COVID-19 has been a major exception to this law, with the number of COVID-19 trials being 7 to 20 times greater than that implied by the historical relationship between market size and R\&D effort.

\#3. Based on the COVID-19 episode we find that, even in the short-term, the aggregate elasticity of science and innovation can be very large. We document that in the initial months of the pandemic up to 50\% of newly started trials were directed towards COVID-19. And, despite the large increase in COVID-19 R\&D, overall new clinical trials increased by $38 \%$ in 2020 with little crowding out of R\&D effort for other diseases.

\#4. We find that public research institutions were a key driver of the COVID-19 R\&D effort—accounting for $70 \%$ of all COVID-19 clinical trials globally, and being 10 percentage points more likely to conduct a COVID-19 trial relative to private firms. In addition, studying the speed of COVID-19 vaccine development, we find U.S. and Chinese candidates were on average 2 months faster than candidates from other countries. This crucial boost in speed was possibly due to greater provision of early-stage incentives by the policy response in these countries, including through programs such as Operation Warp Speed (OWS).

Our paper hopes to inform ongoing work in innovation economics. Even after six decades of active research since the seminal ‘The Rate and Direction of Inventive Activity' 1960 NBER conference, many important ques-

\footnotetext{
${ }^{4}$ Previous studies focusing on within-disease variation have often found an elasticity of research effort to market size below one (see e.g. Giacotto, Santerre, \& Vernon 2005, Civan \& Maloney 2009). However, less attention has been paid to why this elasticity is below one and on the cross-sectional variation across diseases.
} 
tions in innovation economics remain open. For instance, at the beginning of 2021, Gross \& Sampat (2021) wrote: "Though economists' understanding of crisis innovation is growing, many questions remain...How elastic are different organizations, researchers, and fields in their ability to pivot to crisis innovation problems on short notice?" Our paper tries to shed light on some of these questions, and below we discuss three broad implications for innovation economics going forward.

First, our findings suggest that boosting market size by itself may not be an effective tool to scale up innovation to fight large diseases - due to the law of diminishing effort. That is, the presence of the concavity blunts the effect of the classic market size incentives favored in economics, since $d\left(\ln z_{j}\right) / d\left(\ln Y_{j}\right)=(1-\beta)<1$. Such a concavity could arise due to various mechanisms, and in our paper we discuss three possible candidates: (a) decreasing returns to scale due to a scarcity of ideas or talent, (b) risk aversion among firms' management, and (c) disease-specific ex-post taxation (paradox of market size). From one perspective, the concavity may reflect a genuine technological constraint in the economy without creating an inefficiency (e.g. due to the scarcity of ideas). By contrast, from another perspective, some of these mechanisms could be associated with market failures (for instance disease-specific taxation or when firm risk aversion is greater than that of the social planner's), in which case the law of diminishing effort could lead to inefficient outcomes and under-investment in $R \& D$ even beyond that suggested by classic economic theory. ${ }^{5}$

The economic literature has long emphasized that market size is a powerful force shaping pharmaceutical innovation (Acemoglu \& Linn 2004, Finkelstein 2004, Yin 2008, Blume-Kohout \& Sood 2013, Kyle \& MacGahan 2012, Dubois et al. 2015, Clemens \& Rogers 2020, Clemens \& Olsen 2021). However, it has also acknowledged the possibility that market size may provide insufficient incentives for innovation in certain therapeutic areas. This includes diseases afflicting a small number of patients, cancers that have relatively long survival times (Budish, Roin \& Williams 2015), and especially diseases primarily affecting patients in developing countries (Kremer 2000, 2002). Our findings flip this traditional thinking on its head by suggesting that market size may also provide insufficient incentives for the largest diseases.

While we hope our finding spurs future empirical work to examine the underlying mechanisms that give rise to the law of diminishing effort, one possible mechanism worth exploring could be what we call the paradox of market size. Our model section develops the argument more formally, and we give a brief sketch of the idea here using the experience of COVID-19. While the development of a COVID-19 vaccines and treatments could generate billions of dollars for some pharmaceutical companies, there are already public concerns and accusations of exploiting the pandemic. This has led some companies, e.g. Johnson \& Johnson and AstraZeneca, to pledge

\footnotetext{
${ }^{5}$ Classic economic theory suggests that market economies are likely to under-provide innovation because of the public good nature of knowledge (Arrow 1962, Bloom, van Reenen, \& Williams, 2019). And, this problem may be exacerbated for particular types of innovation due to additional market or policy failures (Budish, Roin \& Williams 2015, Kremer \& Snyder 2015, Kremer 2000).
} 
they will not profit from their vaccine during the pandemic. ${ }^{6}$ This experience is illustrative of a type of ex-post drug-specific tax that pharmaceutical companies may face (as opposed to say information technology companies), whereby if the drug is likely to serve a large population then it becomes politically/socially untenable for the company to make large profits from the drug's success. Moreover, the bigger the market size the stronger the political pressure for governments is likely to be to ensure the drug companies do not charge a high price for access to the vaccines or treatments. ${ }^{7}$ Thus, this force ('the paradox of market size') moderates the classic market size mechanism that predicts the bigger the market size the more incentives for innovation-and could be one reason why firms may under-investment in R\&D to fight the deadliest diseases. Moreover, since this is a political economy constraint, addressing such inefficiencies may be difficult due to commitment problems inherent in politics—in line with Daron Acemoglu's (2003) work on "Why Not a Political Coase Theorem?"

Second, our findings suggest that public research institutions, government-led incentives, and non-monetary incentives are important drivers of innovation. ${ }^{8}$ The current thinking in the economic profession is still dominated by a private sector market-size driven perspective on what drives innovation. Consistent with widespread beliefs in the economics profession and among policymakers, enhancing market size has been seen as key to accelerate COVID-19 innovation. ${ }^{9}$ For instance, in a survey of prominent economists conducted by the University of Chicago Initiative on Global Markets (IGM) on June 23rd, 2020, the questions were focused on seeking economists' view on how much acceleration in COVID-19 innovation could be achieved by enhancing the market size; meanwhile early stage stage incentives, or the role of the public sector were not even considered in

\footnotetext{
${ }^{6}$ Talking on BBC Newscast, Sir Mene Panagos, Executive Vice-President of BioPharmaceuticals R\&D at AstraZeneca, said "We have also been very clear that we are doing this not for profit, I think that is important, hopefully that gets rid of one of the bits of baggage that surrounds the pharmaceutical industry. We are commercial businesses and we do make a profit but in this particular instance, the vaccine, given the situation the world is finding itself in, given how deadly this virus has proven to be, our aim is to get this vaccine as globally and equitably as possible around the world, not just the developed world, the U.S., Europe and the rich countries but to low and middle income countries as well, and to do that you have to make the vaccine affordable (...) and we are committed to doing it not for profit."

${ }^{7}$ Some speciality cancer drugs_-such as imatinib (Gleevec) — have been priced above USD 100,000 per year (Dusetzina 2016). Such levels are simply inconceivable for very common diseases given the fiscal strain (and costs for insurers) they would create. Previous literature (Golec, Hegde \& Vernon 2010, Koijen, Philipson, \& Uhlig 2016) has shown that the mere threat of government interventionmostly in the form of price regulation, effectively a form of ex-post tax — lowers the stock market returns of pharmaceutical companies. However, the literature has paid less attention to the possibility that such intervention may be more likely for large diseases.

${ }^{8}$ The contribution of the public sector in generating basic knowledge that private pharmaceutical firms can build upon is certainly appreciated and increasingly quantified (see e.g. Azoulay et al. 2019, Kao 2019). However, their role in pharmaceutical development beyond basic research has not received much attention. Public organizations have often, for instance, taken a leading role in developing vaccines. On the role of the state in innovation more generally see Mazzucato (2013).

${ }^{9}$ To address insufficient incentives for diseases that affect a small number of patients, the U.S. Congress passed the Orphan Drug Act in 1993, whose main provision was a seven-year market exclusivity for companies that developed an orphan drug. Similarly, in 1997 the U.S, Congress enacted a new law providing six months exclusivity to incentivize manufacturers to conduct studies of drugs in children. Michael Kremer has consistently advocated for 'pull' mechanisms that would seek to create markets for vaccines for diseases primarily affecting developing countries (Kremer 2000, Kremer \& Glennerster 2004, Kremer \& Williams 2010). While these initiatives have found to be effective in promoting innovation (Lichtenberg \& Waldfogel 2003, Olson \& Yin 2008, Yin 2008, Kremer, Levin \& Snyder 2020), our point is that enhancing market size is often seen as the main (if not the only) thing policymakers can do to increase innovation in a certain area.
} 
the questions to the panel. ${ }^{10}$ In their responses, $87 \%$ of economists agreed or strongly agreed with the statement that "Government commitments to pay developers and manufacturers above average costs for an effective vaccine or drug treatments for Covid-19 would accelerate production." Yet, to the best of our knowledge, no country committed to pay "above average cost" for an effective vaccine, and despite that multiple successful COVID-19 vaccine candidates have been developed at record speed. ${ }^{11}$ Instead, in our work we find a strong role of public research institutions in driving COVID-19 innovation, accounting for 70\% of COVID-19 clinical trials. ${ }^{12}$ Moreover, when compared to private firms, we find that public research institutions were 10 percentage points more likely to pursue clinical trials to fight COVID-19. In addition, we observe several important COVID-19 pharmaceutical innovations being driven by public research institutions with no explicit monetary incentives. For instance, one of the most important findings with respect to treatment for COVID-19 was based on a publicly-funded clinical trial in the U.K. conducted by a university lab-with no obvious monetary benefits. On June 16th, the NIHR-funded and supported clinical trial identified the steroid dexamethasone to reduce deaths by up to a third among COVID-19 patients on ventilators, and by a fifth for those on oxygen (NIHR 2020). Notably, this study was part of a clinical trial established very early on in March 2020, which through the NIHR's Clinical Research Network the study recruited over 11,500 patients from over 175 NHS hospitals in the U.K by June 2020. Overall, such cases highlight the important role public research institutions can continue play in driving global innovation in the future.

The COVID-19 experience also invites us to re-think the catalyst role of governments in promoting innovation for the greater good. ${ }^{13}$ While various factors played a role in the innovation success-including an intrinsic pursuit of the greater good by many in the global scientific community, prior experience with related virus pathogens, and improvements in manufacturing technology — the role of government-led incentives and funding is also an important part of the success story. Not only did several governments prioritize COVID-19 R\&D as a matter of political urgency, but many also provided a range of early-stage incentives. We use the term "early-stage incentives" to refer to incentive schemes for R\&D that were not conditional on eventual success. For instance, through Operation Warp Speed the U.S. provided funding support to fund clinical trials and

\footnotetext{
${ }^{10}$ Azoulay \& Jones (2020) did, however, propose a COVID-19 Defense Research Committee that would fund innovations and scale successful advances; loans that would be forgivable later, based on actual investment in COVID-19-related innovations; as well as additional support through the R\&D tax credit system.

${ }^{11}$ Even the advance purchase contracts for various vaccine candidates in the U.S. Operation Warp Speed (OWS) were at below market price. Effectively, these advance contracts worked more as a reward for the government in case their initial support paid off (akin to the option to obtain the first batch of products in exchange for providing crowdfunding support on platforms such as Kickstarter).

${ }^{12}$ Many clinical trials are sponsored by universities and hospitals. In 2019 , around $60 \%$ of clinical trials across all diseases were sponsored by public organizations. Within the field of infectious diseases, specialized institutions have been at the forefront of both basic and applied research. These include, the Pasteur Institute in France, the Koch Institute in Germany, the Walter Reed Army Medical Center and the National Institute for Allergy and Infectious Diseases in the U.S. or the Statens Serum Institut in Denmark.

${ }^{13}$ We use the term "catalyst" here to emphasize that the effective government help for innovation is likely to go beyond the capital provision role. Instead, up-front mission-oriented support for R\&D-even with limited financing resources-may act as a catalytic intervention that can increase the speed and success of directed innovative activity.
} 
manufacturing capacity for various vaccine candidates. In this context, much of U.S. private sector effort that succeeded in bringing vaccines and treatments to the market in record time, benefited from such government support. Similarly, many clinical trials in China were government guided through their public research institutions or state-owned companies (e.g. Sinopharm), such that the government prioritized COVID-19 R\&D and made resources available for those priorities.

Third, based on the experience of COVID-19 our work suggests that the short-term aggregate elasticity of science and innovation is much larger than expected, raising the distinct possibility of scaling up global innovation in the future. In this context, the experience of COVID-19 suggests that scaling up innovation may require a better understanding of non-monetary incentives and also a more active role by governments in providing early-stage $R \& D$ incentives. ${ }^{14}$ While we have discussed the size of $R \& D$ response and have also studied the subset of clinical trials for COVID-19 vaccines, we have paid less attention to the optimal composition and quality of research effort that may be affected when innovation is scaled up quickly (see Bryan et al. 2020). Also, one reason for the COVID-19 R\&D exceptionalism could be the newness of COVID19, which could make the expected marginal return from investing in the disease much higher than for other diseases (in the presence of decreasing returns to scale). While this could be an important contributing factor, our data does not allow us to further investigate this possibility as we have no new diseases of comparable scale in our dataset. ${ }^{15}$ Still, the rapid and large R\&D response to COVID-19 suggests that scarcity of ideas and talent may not be a prohibitive barrier to scaling up innovation—at least for new diseases.

Overall, economists are naturally in favor of market size as a driving force for innovation (i.e. "if the market size of the product is sufficiently large, then innovation will happen.") This view is reflected in the IGM Forum survey mentioned above, but also in various proposals such as Chalkidou et al. (2020), and Snyder et al. (2020). Our findings suggest that enhancing the market size may not be an effective pull for driving innovation for large diseases by itself — and the policymakers might want to complement the market size effect with early-stage incentives and harnessing the power public research institutions and non-monetary incentives. This broader perspective on the drivers of innovation is also consistent with recent work by Ahuja et al. (2020), which argues that in future pandemics, buyers should directly fund manufacturing capacity for vaccines and shoulder most of the risk of failure, while maintaining some direct incentives for speed.

\footnotetext{
${ }^{14}$ Gross \& Sampat (2021) describe U.S. research effort during World War II and emphasize the role of the U.S. Office of Scientific Research and Development (OSRD) in funding and coordinating R\&D effort. In the context of pharmaceutical products for diseases afflicting developing countries, the public sector and philanthropic foundations have often provided early-stage incentives while seeking to retain control of the intellectual property to achieve their goals to develop new affordable products for neglected diseases. The underlying model—described in Moran (2005), Maurer (2006) and Munoz et al. (2015) —is often perceived to have been quite successful but has received relatively less attention among economists.

${ }^{15}$ While we observe only a handful of directed trials (often less than 2) within one year of recent outbreaks of diseases such as SARS-CoV-1, Ebola, or Zika (compared to 1433 new trials for COVID-19 in 2020), the corresponding market size also significantly smaller preventing us from making a meaningful comparison.
} 


\section{Theory}

Our empirical framework is based on an extension of the model presented in Acemoglu and Linn (2004), which studies the impact of market size on innovation. In this section, we describe the key features of the model and its links to our empirical work, while presenting the full model in Appendix 2. Acemoglu and Linn (2004) build a model to link R\&D effort $\left(z_{j}\right)$ for disease $j$ to the market size for the drug $\left(Y_{j}\right)$. We make two key modifications to their model.

Disease-Specific Taxation: First, we allow for disease-specific taxation $\left(\tau_{j}\right)$ to take into account that the de facto tax rate faced by the firm on the profits from a drug may depend on the market size of the disease. Such a de facto tax structure may arise due to different reasons. For instance, governments often pay for drugs on behalf of the citizens-especially that is needed by a large fraction of the population (e.g. vaccines). In such situations, the price received by the drug-maker is determined by a negotiation process with a single buyer (the government), which needs to account for political economy, societal needs, and public image considerations. Moreover, similar considerations may influence the pricing of the drug even when the drug-maker is directly selling to the public - making it harder for the firm to charge a high price for a drug that serves a large segment of the population.

Non-Monetary Incentives for Innovation: Second, we consider the possibility that researchers may have non-monetary motivation $\left(\eta_{j}\right)$, i.e. altruism motive or reputational incentives) to pursue $\mathrm{R} \& \mathrm{D}$ (discussed more below).

Other than these modifications, the setup of the model follows Acemoglu and Linn (2004) closely. ${ }^{16}$

In the model, the discounted value of profits for firms can be expressed by a standard dynamic programming recursion. $V_{j}\left(t \mid q_{j}\right)$, the value of a firm that owns the most advanced drug of quality $q_{j}$ in line $j$ at time $t$, is

$$
r V_{j}\left(t \mid q_{j}\right)-\dot{V}_{j}\left(t \mid q_{j}\right)=\pi_{j}\left(q_{j}(t)\right)-(1-\eta)\left[n_{j}(t) V_{j}\left(t \mid q_{j}\right)\right]
$$

where $\pi_{j}\left(q_{j}(t)\right)$ is the flow profits, $r$ is the discount rate, and $z_{j}(t)$ is $\mathrm{R} \& \mathrm{D}$ effort at time $t$ on this line by other firms. The value of owning the best technology in line $j, r V_{j}\left(t \mid q_{j}\right)$, is equal to the flow profits, $\pi_{j}\left(q_{j}(t)\right)$, plus the potential appreciation of the value, $\dot{V}_{j}\left(t \mid q_{j}\right)$, and takes into account that at the flow rate $n_{j}(t)$ there will be an innovation, causing the current firm to lose its leading position and to make zero profits thereafter. The parameter $\eta \in[0,1]$ captures the non-monetary incentives and represents the degree to which the firm cares about bringing the innovation to market-independent of the possibility of its innovation being replaced by a

\footnotetext{
${ }^{16}$ To capture the effect of limited supply of top researchers, we also allow for economy-wide decreasing returns to scale to R\&D effort (instead of disease-specific decreasing returns to scale as in the original model).
} 
new entrant at a future date. Another way to interpret the case of $\eta>0$ is that if a firm gains reputation value from being first to bring an innovation to the market then it would still derive non-monetary benefits from the innovation even after it has been replaced by new entrants (thereby blunting the standard Arrow replacement effect as shown in Aghion and Howitt, 1992).

To account for the disease-specific progressive taxation we suppose $\tau_{j}=1-\alpha Y_{j}^{-\beta}$ for some non-negative constants $\alpha, \beta$ with $\beta<1$. Then, under the model's assumptions, the equilibrium steady state effort for disease $j$ can be represented as:

$$
\ln z_{j}^{S}=\text { Constant }+\eta+(1-\beta) \ln Y_{j}
$$

That is, $\log \mathrm{R} \& \mathrm{D}$ effort is a function of the $\log$ market size $Y_{j}$, non-monetary incentives $\eta$, and a constant term. Here, the elasticity of $\mathrm{R} \& \mathrm{D}$ effort with respect to market size is given by $1-\beta$. This is the relationship we estimate in Table 1. Note that in the Acemoglu and Linn (2004) model there is no role for taxes or nonmonetary incentives, such that $\beta=0$ and $\eta=0$. This implies that the elasticity of R\&D effort with respect to market size is 1 in their baseline model.

\section{Data and Methods}

Measuring $R \& D$ Effort. In much of our empirical work, the key outcome variable will be disease-specific $\mathrm{R} \& \mathrm{D}$ effort. Following much of the literature on pharmaceutical innovation (see e.g. Yin 2008, Kyle \& McGahan 2012, Blume-Kohout \& Sood 2013, Dranove, Garthwaite \& Hermosilla 2012, Budish, Roin \& Williams 2015), we use the number of new clinical trials as a measure of R\&D effort. Alternative measure include patents (Qian 2007), R\&D spending (Ward \& Dranove 1995, Giaccotto, Santerre \& Vernon 2005), or the number of products in developments but neither of these are readily available for COVID-19 R\&D and very recent periods more generally. ${ }^{17}$ Alternatively, others (including Acemoglu \& Linn 2004, Dubois et al. 2015) have used innovation outcomes such as new drug approvals by the FDA. However, these are also not well suited to study a very recent phenomenon.

Measuring Market Size. A key explanatory variable of interest for us is the potential market size for the disease. The literature has also used different approaches to quantify potential market size. For instance, Dubois et al. (2015) measures expected market size as the lifetime revenue accruing to the average product in a given disease category. Lichtenberg (2005) and Civan \& Maloney (2009) use Disability-Adjusted Life Years (DALYs) and disease mortality respectively. By contrast, Acemoglu \& Linn (2004) derive an income-based

\footnotetext{
${ }^{17}$ For instance, patent applications are only observable when they are published 18 months after application. It is thus too early to observe any patent application related to COVID-19
} 
measure of market size, which combines the number of consumers weighted by their incomes. In line with one strand of the literature, we construct an income-based measure of potential global market size. First, for the year 2017, we sum disease-level mortality data at the national level weighted by national GDP per capita and the value of statistical life (VSL) of USD 1 million for the mean global citizen. ${ }^{18}$ This measure is based on our formal framework in the appendix.

Clinical trials data. We use clinical trials data from clinicaltrials.gov, a registry of trials run by the U.S. National Library of Medicine. Initially meant as a resource for patients to identify experimental treatments, the registry has become a key source of information on clinical trials activity globally. ${ }^{19}$ It currently includes more than 300,000 registered trials from 209 countries. Unlike competitive intelligence database sold by private vendors, it is freely available, and can be downloaded in bulk. Data fields included in the clinicaltrials.gov records, include the study title, condition, the intervention, outcomes, eligibility criteria, target enrollment, study phase, the lead sponsor, locations, registration date and state date and contact information of the lead investigators. Most relevant for us are the sponsor class (industry or not), the location of the clinical trials, the study phase, the starting date and the medical condition that the trials addresses. That field is a free form entry field and thus does not follow a standard vocabulary. However, trials for COVID-19 are specifically tagged by the National Library of Medicine, ${ }^{20}$ and we manually developed a cross-walk to the disease classification. For the purpose of this study, we focus on clinical trials in phase 1,2 and 3 and exclude phase 4 trials and trials not associated with a phase. ${ }^{21}$

Mortality data. We use disease-level mortality data from the Global Burden of Disease (GBD) Project. This project is a major data collection effort led by the Institute for Health Metrics and Evaluation and involving thousands of researchers (Global Burden of Disease Collaborative Network 2017, GBD 2015 Mortality and Causes of Death Collaborators 2016). Data released in open access by the project includes estimates of number of deaths by cause and country. We use the latest data available as of May 2020 which covers mortality in the 2017 calendar year. Causes of deaths in GBD are categorized in four levels from general to more specific. For instance, a death attributed to acute myeloid leukemia would be categorized as a death from non-communicable diseases (level 1), from a neoplasm (level 2), from leukemia (level 3) or from acute myeloid leukemia (level 4). Our preferred classification is the level 3 which includes 170 causes of deaths. Since we are interested in

\footnotetext{
${ }^{18}$ The particular value of statistical life (VSL) we choose is inconsequential for our analysis since it just multiplies all diseases burden by a constant.

${ }^{19}$ Staring in 2005, the International Committee of Medical Journal Editors required clinical trials published in any of their affiliated journals to be pre-registered.

${ }^{20}$ Based upon the keywords 'COVID-19', 'COVID, 'SARS-CoV-2, 'severe acute respiratory syndrome coronavirus 2', '2019-nCoV', '2019 novel coronavirus', 'Wuhan coronavirus'

${ }^{21}$ Phase 1 clinical trials aim to assess safety and appropriate dosing while phase 2 and 3 assess efficacy and side effects. Phase 4 monitor the long-term effects of drugs that are already on the market. Trials not associated with a phase include monitoring of symptoms without intervention and non-pharmaceutical interventions.
} 
diseases and their mortality, our analysis excludes injuries as well as diseases with negligible death burden (e.g. acne), resulting in a sample of 75 diseases, to which we add COVID-19 as a separate disease. From the raw data, we compute both the global burden of disease, and the share of deaths occurring in high-income countries, upper middle-income countries, lower middle-income countries, and low-income countries, based on the 2019 World Bank classification of countries. In addition to the 2017 global death burden, the GBD database also provides information on changes in the death burden from 2007 to 2017, which we incorporate in our dataset.

Vaccine development data. We use the World Health Organization (WHO) COVID-19 candidate vaccine landscape database, which compiles detailed information on COVID-19 vaccine candidates in development. ${ }^{22}$ The landscape provides summary tables of COVID-19 vaccine candidates in both clinical and pre-clinical development; tracks the progress of each vaccine from pre-clinical, Phase 1, Phase 2, through to Phase 3 efficacy studies; and includes information on key attributes of each vaccine candidate. The database is updated periodically every few weeks, and using the different vintages of the database (between February 2020 to December 2020) we are able to construct the timing of when the different candidates move from one clinical stage to another. In addition, based on manual search for each vaccine candidate, we code the location of the developer, and whether each candidate is being developed by private sector entities, a public entity, or by a collaboration between public and private entities. Overall, we have 222 vaccine candidates in development by mid-December 2020, and our analysis of speed and success of COVID-19 vaccine R\&D effort in Section 6 is based on this dataset. The dependent variables are (a) the month in which the vaccine candidate first appeared as a pre-clinical candidate in the dataset, (b) an indicator variable that takes the value of one if the vaccine candidate entered clinical trials (i.e. graduated from pre-clinical to Phase 1 or Phase 1/2), and (c) number of phase progressions experienced by the vaccine candidate in the year 2020, as a measure of vaccine R\&D success. In addition, the vaccine developer location, the private/public status, and the month in which the candidate entered the preclinical phase are used as explanatory variables. Descriptive statistics for the vaccine data are in Appendix Table A3.

Disease cross-section data set. We form a cross-section of diseases, with research effort (average yearly number of new trials from 2015 to 2019) and market size as previously defined. We include a number of additional variables, including Disability Adjusted Life Years (DALYs), whether the disease is an infectious disease, whether the disease is a cancer, the share of the disease burden in high-income countries and the change in disease burden from 2007 to 2017. Finally, as a measure of difficulty of the disease in terms of $\mathrm{R} \& \mathrm{D}$ we compute the ratio of phase III trials to phase I trials, roughly reflecting the share of drug candidates that progress to phase III from phase I. Descriptive statistics for the 75 diseases in our sample are displayed in

\footnotetext{
${ }^{22}$ The data is available at https://www.who.int/publications/m/item/draft-landscape-of-covid-19-candidate-vaccines.
} 
Appendix Table A1.

COVID-19 entry data set. Based on the clinicaltrials.gov data, we form a cross-section of all organizations that conducted at least two clinical trials from 2015 to 2019. The original data includes information on whether the organization is in industry (as opposed to hospitals and universities which also conduct clinical trials). We deduce the location of an organization based on the location of its clinical trials (complemented with manual checks). We measure the number of COVID-19 clinical trials started by the organization in 2020. We construct the total number of trials undertaken by the organization from 2015 to 2019 as well as an indicator variable for whether the firm conducted at least one trial related to lower respiratory or upper respiratory infections from 2015 to 2019. Descriptive statistics for the 1,773 organizations in our sample are displayed in Appendix Table A4.

\section{Law of Diminishing Effort}

The main result presented in this section is that global pharmaceutical R\&D activity-measured by clinical trials - typically follows the 'law of diminishing effort': i.e., the elasticity of R\&D effort with respect to market size is about $1 / 2$ in the cross-section of diseases. We first present the empirical findings, and then discuss possible mechanisms that can lead to the empirically-observed law of diminishing effort.

\subsection{Results}

To establish this result, we investigate the relationship between market size and research effort at the disease level. For the moment, we exclude COVID-19 from this analysis - in the next section we will discuss the intensity of the COVID-19 R\&D effort in light of the COVID-19 market size. We measure R\&D effort as the average yearly number of new clinical trials by disease between 2015 and 2019. Market size is defined by the global burden of disease in terms of deaths with an adjustment for its geographic distribution, as discussed in the data section.

Regressing research effort on market size in the cross-section of 75 diseases, ${ }^{23}$ we find that that an $1 \%$ increase in market size is associated with a $0.43 \%$ increase in research effort (cf. Table 1 column 1), implying an R\&D effort elasticity of 0.43 . To investigate the stability of this relationship within a more homogeneous set of diseases, we restrict the sample to cancers and then to infectious diseases (cf. Table 1 columns 2 and 3 respectively). In the cancer subsample, we get an elasticity of 0.61 and for infectious disease an elasticity of 0.47 . The $R^{2}$ of the univariate regressions range from about 0.3 to 0.5 .

\footnotetext{
${ }^{23}$ This regression directly corresponds to the equation linking market size to R\&D effort in the model presented in Appendix 2.
} 
One may worry about reverse causality such that market size could be the result of innovation, rather than its determinant. In this context, note that our measure of market size reflects income-weighted mortality risk instead of actual sales, which mitigates such concerns. Nevertheless, to the extent that mortality risk may be influenced by past innovation, we control for changes in mortality risk in column 4 , along with a number of other plausible determinants of research effort. ${ }^{24}$ While the change in disease burden is positively and significantly associated with higher research effort, the coefficient on market size is lower than in the main specification at 0.36. Overall, these results (also displayed graphically in Figure 1) paint a consistent picture with estimated elasticities of R\&D effort to market size well below one, and distributed around 1/2.

Our results are consistent with numerous prior studies—using a variety of market size, R\&D effort measures, and empirical strategies - that found elasticities of R\&D effort to market size well below one (cf Table A2). Dubois et al. (2015) note "The previous literature generally finds elasticities for new drug products [with respect to market size] to be in the vicinity of 0.5 ". For instance, Giacotto, Santerre, \& Vernon (2005) find that an $1 \%$ increase in the pharmaceutical price index leads to a $0.58 \%$ increase in R\&D spending. Similarly, Civan \& Maloney (2009) conclude that an $1 \%$ increase in expected US entry price leads to $0.5 \%$ increase in the number of drugs in the drug development pipeline. Other studies often find similar results. ${ }^{25}$ These studies typically use within-disease variation in market size, for instance due to demographic or policy changes. However, we prefer to use the cross-section of diseases as we want to use the relationship to predict research effort for a new disease-COVID-19. We are not aware of previous studies estimating the elasticity of R\&D effort to market size using a cross-section of diseases for worldwide trials.

(insert Table 1 and Figure 1 about here)

\subsection{Possible Mechanisms that Lead to the Law of Diminishing Effort}

The consistent finding in the literature and in our paper that the elasticity of R\&D effort with respect to market size is about $1 / 2$ is what we call the 'law of diminishing effort' in R\&D. We next turn to discussing possible

\footnotetext{
${ }^{24}$ Disability adjusted life years (DALYs) is another common measure of disease burden. To reduce collinearity with market size we control DALYs over deaths rather than DALYSs directly. Products for diseases that have a higher share of their mortality in rich countries may be easier to monetize - above and beyond the direct mechanical effect on market size. As a measure of difficulty of the disease in terms of R\&D we compute the ratio of phase III trials to phase I trials, roughly reflecting the share of drug candidates that progress to phase III from phase I.

${ }^{25}$ Ward \& Dranove (1995) associate a 10 percent increase in demand in a therapeutic area with a 5-8 percent increase in R\&D spending. In a cross of section of cancers, Budish, Roin \& Williams (2015) estimate an elasticity of research effort with respect to market size of 0.24 (a side result in their analysis of effective patent length on research effort). Also in a cross-section of cancers, Lichtenberg (2007) finds an elasticity of 0.53 for the number of chemotherapy regimens with respect to the number of cases. BlumeKohout \& Sood (2013) find an elasticity of 2.8 of R\&D effort to changes in market size due to Medicare expansion. However, as noted in Dubois et al. (2015), this may be due to the Medicare expansion also impacting cash-flow in addition to changing market size for new products. See Dubois et al. (2015) for a comprehensive literature review.
} 
factors that may give rise to such a relationship. We present three broad possible mechanisms that could lead to the empirically-observed law of diminishing effort in R\&D: (a) Scarcity of Talent and Ideas, (b) Risk Aversion, and (c) Disease-Specific Taxation and the Market Size Paradox.

First, there may be decreasing returns to scale, such that doubling the number of clinical trials can lead to an increase in average $R \& D$ cost per trial, or can reduce $R \& D$ quality per trial. Such decreasing returns to scale could arise if (good) ideas to pursue in R\&D are scarce-a central theme in the work of Suzanne Scotchmer (see e.g. Scotchmer 2004). ${ }^{26}$ Bloom et al. (2020) present evidence across a range of context that research effort is rising substantially, while research productivity is declining-consistent with ideas are scarce and getting harder to find. ${ }^{27}$ Within the pharmaceutical sector, larger firms often seek to replenish their R\&D pipeline through acquisitions (Higgins \& Rodriguez 2006, Krieger, Li, \& Thakor 2018). If ideas were not scarce, pharmaceutical would rely on in-house development in order to avoid information asymmetries associated with acquisitions. However, one piece of evidence that is difficult to reconcile with scarce ideas is that while the elasticity of research effort with respect to research effort is below one, the elasticity of innovation (as opposed to research effort) with respect to market size is often found to be well above one (Acemoglu \& Linn 2004, Finkelstein 2004). If an increase in market size pushes researchers to pursue marginal ideas of lower quality-as one would expect if ideas are scarce — then innovation should react relatively less to changes in market size.

An alternative source of decreasing returns to scale could come from a scarcity of skilled R\&D personnel. If the number of talented researchers/scientists are in scarce supply, then firms would face an upward sloping supply curve that makes it costlier to increase directed $R \& D$ towards specific diseases. For instance, in the case of COVID-19, many vaccine candidates that entered the race to find a successful vaccine early, also had prior experience with vaccine candidates for Ebola or SARS-COV-1. At the level of the individual scientist, the costs to switch to a different topic appear to be high (Myers 2020). Overall, either scarcity of talent and ideas could be one candidate explanation for the law of diminishing effort.

Second, the management of R\&D firms may be risk averse. For instance, recent work by Lovallo et al. (2020) document that managers in large firms exhibit high degrees of risk aversion, and routinely quash risky ideas in favor of marginal improvement or safe investments. Moreover, as noted in Asplund (2002), even when owners wish to maximise expected profits, the delegation of control to a risk-averse manager may cause the firm to behave in a risk-averse manner. In our case, presence of risk averse firm management would imply that due to decreasing marginal utility over profits, the firm management may be less enticed by the incentive of capturing a very large market for drugs if it comes with the risk of having a more un-diversified R\&D portfolio. Such

\footnotetext{
${ }^{26}$ Acemoglu \& Linn (2004) consider such a case in an extension to their model. Also see the model in Clemens and Olsen (2021).

${ }^{27}$ Along the same lines, there has also been much discussion around the pharmaceutical industry's 'productivity crisis' reflected in rising R\&D cost per approved drug see e.g. Cockburn (2007).
} 
concentration risk in the $\mathrm{R} \& \mathrm{D}$ portfolio can be a serious deterrent as not all candidate drugs graduate from the clinical stage to the licensed products stage, creating a tendency for management teams to avoid putting their eggs in a few baskets. This could give rise to law of diminishing effort at the firm level, which could in turn create a law of diminishing effort in the aggregate. Another reason why risk aversion could lead to the law of diminishing effort is the 'winner take all' dynamics. If a few successful candidates (for instance those that manage to become the first few to obtain licensure) are likely to capture a dominant share of the profits for each disease, then that could deter risk-averse firms to enter the race to find cures ex-ante. Under certain market structures this could lead to a pattern akin to the law of diminishing effort in the aggregate.

Third, we conjecture the law of diminishing effort could arise due to the difficulty in monetizing innovation that benefits a large group of people. We call this the 'market size paradox.' The argument is developed more formally in Appendix 2, and we sketch the key intuition here. In the case of COVID-19, while the development of a vaccines and treatments could generate billions of dollars for some pharmaceutical companies, there are already public concerns and accusations of exploiting the pandemic. This has led some companies, e.g. Johnson \& Johnson and AstraZeneca, to pledge they will not profit from their vaccine, although they have suggested this would be limited to the time during the pandemic. This experience is illustrative of a type of ex-post drugspecific tax that pharmaceutical companies may face (as opposed to say information technology companies), whereby if the drug is likely to serve a large population then it becomes politically or socially untenable for the company to make large profits from the drug's success. Moreover, the bigger the market size the stronger the political pressure for governments is likely to be (due to the size of affected electorate) to ensure the drug companies do not charge a high price for access to the vaccines or treatments. Thus, this force moderates the classic market size mechanism that predicts bigger the market size the more incentives for innovation. By contrast, the paradox of market size suggests, the bigger the market size the higher the ex-post taxation of profits-thereby blunting the incentives for innovation. Therefore, one reason for the 'law of diminishing effort' could be that ex-post tax rate rises with the market size. That is, if disease-specific taxes are increasing with market size, we may have a concave relationship between market size and innovation: innovation effort normally increases with market size, but at a decreasing rate. In fact, an increase in market size may even reduce $R \& D$ due to this effect.

While bringing additional evidence to empirically disentangle the drivers of the law of diminishing effort is beyond the scope of this paper, the discussion of potential mechanisms here could serve as a guide for future work. 


\section{The R\&D Response to COVID-19}

The main results presented in this section is that COVID-19 has been a major exception to the law of diminishing effort, with the number of COVID-19 trials being 7-20 times greater than that implied by its market size; and the large increase in COVID-19 R\&D did not lead to sizable crowding out of R\&D effort for other diseases. These results are based on the findings of the next five sub-sections that examine (a) the size of COVID-19 $R \& D$ relative to total $R \& D$, (b) how the overall $R \& D$ effort across all trials were impacted by COVID-19, (c) how much crowding out occurred due to COVID-19 R\&D, (d) the actual COVID-19 R\&D vs. the expected COVID-19 R\&D effort implied by its market size under various epidemiological and economic assumptions, and (e) Implications for Aggregate R\&D Elasticity.

\subsection{What Was the Size of COVID-19 R\&D Relative to Total R\&D?}

We begin by asking: how large is the COVID-19 R\&D effort compared to other the R\&D effort for other diseases? In our data, 1,433 trials devoted to COVID-19 were started in $2020 .{ }^{28,29}$ To put this number in perspective, the total number of trials started in 2019 was slightly above 3,500 .

In Figure 2, we report the ratio of new COVID-19 trials to all newly started trials on a monthly basis. In March 2020, around 13\% of newly started trials were on COVID-19. Just a month later, the same figure had jumped to close to $50 \%$ before gradually declining to around $25 \%$ by December 2020 . Comparing broad geographic areas (Appendix Figure A1), the U.S. and Europe have followed similar trajectories although in Europe the share of newly started COVID-19 trials peaked as high as 75\% in April 2020, while it never exceeded $50 \%$ in the U.S. Meanwhile, in China the share of COVID-19 trials among newly started trials was around $40 \%$ in February but it quickly decreased to below 20\%, in line with the early persistent decline in active COVID-19 cases in China.

(Insert Figure 2 around here)

The figures presented suggest that the COVID-19 R\&D effort is large both in absolute and relative terms. The scale and speed of the COVID-19 R\&D has been noted by other observers (e.g. Bryan et al. 2020, Le et

\footnotetext{
${ }^{28}$ As discussed in the data section, the clinicaltrials.gov database specifically tags COVID-19 trials based on a combination of keywords. Since we restrict our attentions to trials that are in phase 1, 2 or 3, we have a lower number of trials than the headline figure reported on clinicaltrials.gov.

${ }^{29}$ While we have discussed the size of R\&D response and have also studied the subset of clinical trials for COVID-19 vaccines, we have paid less attention to the optimal composition of research effort between re-purposed drugs vs. novel drugs/vaccines. In this context, Bryan et al. (2020) build a model to illustrate that during crises like the COVID-19 pandemic, the direction of research by endogenously affecting market structure, such that there could be situation in which the market for invention leads to too much work on "quick" projects like re-purposed drugs and too little work on long-run projects like vaccines.
} 
al. 2020).

\subsection{How Did COVID-19 Impact the Overall R\&D Effort for All Diseases?}

While the size of the aggregate market for pharmaceutical innovation is constantly changing with demographic and economic growth, the COVID-19 pandemic is a rare instance of a discrete shift. Our model predicts that such a shift would increase total effort for all diseases as well as reduce effort directed towards diseases other than COVID-19. However, the relative magnitude of these phenomena is an empirical question. We examine the effect of the COVID-19 outbreak on total effort first, before turning our attention to the crowding out of effort directed towards other diseases in the next subsection.

(insert Figure 3 about here)

Figure 3 displays the number of new clinical started monthly (3-months moving average). From 2015 to 2019, the average number of new clinical trials started monthly worldwide was remarkably stable around 300. In the second quarter of 2020 , the number of new clinical trials started averaged slightly above 450 , a $50 \%$ relative increase compared to the pre-pandemic average. ${ }^{30}$ The total number of trials started in 2020 is up by $38 \%$ compared to the total number of trials started in 2019.

This data suggests a large response of total pharmaceutical effort to the shock in the demand for pharmaceutical innovation induced COVID-19. The increase in total R\&D effort is all the more remarkable given that the pandemic could have affected the supply side of $\mathrm{R} \& \mathrm{D}$, for instance by making it risky or difficult to bring patients to medical facilities to administer treatments or make measurements. Additionally, the pandemic may have disrupted the productivity of researchers through increased child care obligations and reduced access to certain facilities (Myers et al. 2020).

\subsection{Did COVID-19 R\&D Crowd Out R\&D for Other Diseases?}

As we have seen, a great deal of R\&D effort has been directed towards COVID-19, and total pharmaceutical R\&D has substantially increased. But how has the COVID-19 outbreak changed the intensity of R\&D effort for other diseases?

Proposition 1 of the model predicts that economy-wide decreasing returns will lead to such crowding out. To investigate the possibility of crowding-out more systematically, we compare clinical trials at the disease and

\footnotetext{
${ }^{30}$ Distinguishing among broad geographic region (Appendix Figure A2), we observe similar patterns in the U.S. as in the world as a whole. In Europe, a sharp increase in new trials was followed by an equally sharp decrease while in China the number of new trials remained stable.
} 
quarter level. We first construct a panel of diseases with two periods: April to December 2019 and April to December 2020, excluding COVID-19 from the panel. We then estimate a Poisson model with new trials on the left hand side and a COVID-19 outbreak indicator and disease fixed effects on the right hand side. The COVID19 outbreak indicator variable turns to one in the April to December 2020 and is zero otherwise. Considering clinical trials worldwide, we find that the COVID-19 outbreak is associated with a $5 \%$ reduction in the number of clinical trials on average (cf. Table 2 panel A column 1).

(insert Table 2 and Figure 4)

Finally we visualize the crowding-out by disease in Figure 4, with trials started from April to December 2019 on the horizontal axis and trials started from April to December 2020 on the vertical axis. The crowding out is overall modest in size, though noticeable for some of the larger diseases.

\subsection{Actual vs. Expected COVID-19 R\&D Based on Market Size}

In this sub-section we compare the actual COVID-19 R\&D effort to what one would expect based on its potential market size. To make this comparison we need estimates of the perceived direct burden of disease for COVID-19 in the year 2020. In line with our measure of the market size for other diseases, we only focus only on the direct burden of COVID-19, and do not include the large indirect costs arising due to lockdowns and other non-pharmaceutical interventions undertaken to limit COVID-19 mortality. This is because we are interested in the part of the surplus that R\&D firms can capture in order to evaluate how they reacted to the outbreak of COVID-19.

To derive the expected number of COVID-19 trials based on potential market size, we combine an estimate of (a) the relationship between research effort and potential market size, with (b) an estimate of the potential market size for COVID-19. The computation of (a) is based on a regression of log research effort on log market size, which yields a point estimate of 0.43 (See Table 1 column 1).

For (b), we conceptually think of the COVID-19 pandemic as a one-off R\&D opportunity for firms, such that in the short run the global death burden would rise by x million due to COVID-19 deaths. In our exercise, this would create an incentive for firms to front-load COVID-19 R\&D to fight the disease, and then after a couple years return to working on other diseases. Then, the exercise simply boils down to finding an estimate of $\mathrm{x}$ and its worldwide distribution, to evaluate the expected number of trials based on this market size. Thus, for (b), we quantify the likely death burden of COVID-19 in the hypothetical case in which in the absence of non-pharmaceutical control measures $70 \%$ of the world population eventually would get infected. The $70 \%$ 
number accounts for the typical herd immunity estimates, whereby if the disease were allowed to spread, due to herd immunity the number of cases would fall after a certain threshold, thereby infecting only a fraction of the population.

We quantify the COVID-19 potential market size under three different scenarios (by varying the infection fatality rates (IFR)), which when combined with (a) gives us three different estimates of expected number of COVID-19 trials based on its potential market size. ${ }^{31}$

The three different scenarios are used to account for uncertainties in the IFR. For the upper estimate scenario, we assume that the infection fatality ratio is $1 \%$, on the higher side of published estimates. ${ }^{32}$ This is somewhat of a worst-case scenario, as it implies that within a few years COVID-19 would account for about 60 million deaths worldwide, i.e. $x=60 .{ }^{33}$ For the mid-point estimate scenario, we take the IFR to be the bottom range of the estimate, i.e. 0.5\%, which gives us a COVID-19 death burden of 30 million. Finally, for the lower estimate scenario we consider an IFR of $0.1 \%$, which is a tenth of our upper estimate, and yields a total COVID-19 death burden of about 6 million. Note that this number is more than three times above the actual death burden from COVID-19 observed in 2020 (of about 1.9 million deaths) — in a period when no vaccines were commercially available and therapeutics begun rolling out only in the second half of the year. Thus, the death burden in our lower estimate is still likely to be larger compared to the case in which one would extrapolate the death burden based on the experience of 2020. Further, note that here we are being somewhat conservative in assuming that all COVID-19 trials should be front-loaded in the first year under our three scenarios, instead of distributing them over multiple years.

To give a sense of the magnitude of the COVID-19 death burden under the three difference scenarios (5.3, 26.6, and 53.2 million), note that the global burden from all diseases combined has been about 50 million deaths per year in recent years. The largest non-COVID-19 disease in our sample is coronary heart disease, which has an annual death burden of about 9 million. So, another way to interpret the COVID-19 death burdens under the three different scenarios is that it ranges from 0.6 to 6 times the death burden of coronary heart disease for the purposes of our exercise.

(insert Figure 5 and Figure 6 about here )

\footnotetext{
${ }^{31}$ In the presence of the infectious disease externality one may imagine the procurement of drugs may happen through the government . This is consistent with our calculation since we conceptualize the demand for drugs arising from all individuals in the world.

${ }^{32}$ According to the The World Health Organization, estimates of infection fatality rate converge to approximately $0.5-1 \%$ (https://www. who.int/news-room/commentaries/detail/estimating-mortality-from-covid-19, accessed 11 January 2021, Perez-Saez et al. 2020, Stringhini et al. 2020). Earlier studies (Wu et al. 2020, Verity et al. 2020) had slightly higher infection fatality rate estimates.

${ }^{33} \mathrm{We}$ actually use the corresponding potential market size measure (weighting deaths by national GDP per capita). However, we present the more intuitive total deaths to illustrate the underlying assumptions.
} 
Based on the methodology described here, we present our results on the actual vs. expected number of COVID-19 trials in Figure 5. The actual number of trials observed in 2020 was 1,433, meanwhile the expected number of trials based on the market size was 74, 150, and 202 under the different scenarios. Thus, we find that the actual number of COVID-19 trials is about 7 to 20 times greater than that implied by its market size. Using the mid-point estimate for COVID-19 market size from this exercise, we also update the cross-sectional figure for market size and R\&D effort in Figure 6.

\subsection{Implications for Aggregate R\&D Elasticity}

In this sub-section we ask what the COVID-19 R\&D response implies for the aggregate R\&D elasticity. In 2020, the overall R\&D effort as measured by clinical trials increased by $38 \%$ worldwide. As discussed above, this is due to the significant increase in COVID-19 R\&D and simultaneously due to only a modest crowding out of R\&D for other diseases. Using the three different market sizes of COVID-19 from the previous sub-section, we can compute the implied aggregate elasticity under the three different scenarios.

Taking the three different estimates of the COVID-19 death burden, we get that the market size increased by $6.4,32$, and 64 percent under the three different scenarios, implying an aggregate short-term aggregate $R \& D$ elasticity of $6,1.2$, and 0.6 respectively.

This calculation suggests that if the elasticity of COVID-19 can be replicated for other diseases, we can expect global R\&D to scale up significantly in a short time-with an aggregate short-term elasticity of at least about 0.6 , and potentially much higher.

\section{Who Had the Strongest R\&D Response to COVID-19?}

In this section, we examine which sponsors (either firms or public organizations) decided to engage in COVID19 R\&D. As noted by Gross \& Sampat (2021), the elasticity of different organizations in their ability to pivot to crisis innovation problems on short notice is largely an open question and in this analysis we take a step toward answering that question. ${ }^{34}$ The main result in this section is that public research institutions were a key driver of the COVID-19 R\&D effort-accounting for 70\% of all COVID-19 clinical trials globally and being ten percentage points more likely to conduct a COVID-19 trial relative to private firms. In addition, we demonstrate that while experience with respiratory diseases is a strong predictor of COVID-19 entry, the vast

\footnotetext{
${ }^{34}$ Bryan, Lemus \& Marshall 2020 analyze COVID-19 entrant characteristics, including firm age, experience with infectious diseases, vaccines and antivirals, and pipeline size, distinguishing between entry before and after March 11, and repurposed versus new COVID19 drugs. Our results are not directly comparable given the different level of analysis (clinical trials for us versus drug candidates for them) and focus. Further, Clemens and Rogers (2020) study crisis innovation in a historical context. They find that during the Civil War and World War I procurement shocks led to substantial increases in the quantity of prosthetic device patenting.
} 
majority of trials were undertaken by sponsors that did not have such experience.

We first present some descriptive statistics on COVID-19 trials (cf Table A5). Only around 30\% of COVID19 trials have an industry sponsor; close to 70\% of COVID-19 trials were started by a university, hospital, or other public organization (for comparison purposes, only around 60\% of trials started in 2019 had a non-industry sponsor). Around 12\% of COVID-19 trials were undertaken by sponsors that had sponsored a trial on lower or upper respiratory infection prior to the pandemic. The U.S. accounts for around a third of COVID-19 trials started globally, with $23 \%$ of COVID-19 trials taking place in Europe and only $5 \%$ in China.

We analyze next how sponsor characteristics predicts engaging in COVID-19 R\&D in a large cross-section of potential sponsors. ${ }^{35}$ We use as dependent variable either an indicator variable taking value one if the organization started at least one COVID-19 clinical trial, or the number of COVID-19 clinical trials started by the organization. Our variable of interests are size, public/private status location and prior experience with respiratory diseases. ${ }^{36}$

(insert Table 3 about here )

Results are displayed in Table 3. Across the whole sample of organizations, around one in six has conducted one or more COVID-19 trial. Not surprisingly, organization size is a strong predictor of starting a COVID-19 trials and the number of COVID-19 trials. Despite controlling for size, prior expertise in respiratory diseases is associated with a 20 percentage points increase in the propensity to engage in COVID-19 R\&D and a doubling in the number of COVID-19 trials. ${ }^{37}$ Private firms were significantly less likely than public organizations to engage in COVID-19 R\&D. While U.S. and European organizations were equally likely to engage in COVID19 R\&D, Chinese organizations were less likely to engage in COVID-19 and did fewer trials. ${ }^{38}$ Overall, these results suggest that public organizations had a relatively stronger R\&D response to the COVID-19 crisis than private firms.

\footnotetext{
${ }^{35}$ The universe of sponsors that that conducted at least two clinical trials from 2015 to 2019 in the clinicaltrials.gov database.

${ }^{36}$ We proxy size by the number of trials undertaken from 2015 to 2019. Prior experience with respiratory diseases is an indicator variable that takes value one if the firm has conducted at least one trial related to lower respiratory or upper respiratory infections from 2015 to 2019.

${ }^{37}$ The specification on the number of COVID-19 trials is estimated by a Poisson regression. Hence the point estimate of 0.7 translate into a $101 \%((\exp (0.7)-1)$ increase.

${ }^{38}$ However, distinguishing new clinical trials by quarter reveals that Chinese organizations were initially (in Q1) more engaged in COVID-19.
} 


\section{The Speed and Success of COVID-19 Vaccine Effort}

The main result presented in this section is that the speed of COVID-19 vaccine development was on average 2 months faster for U.S. and Chinese candidates, possibly due to early-stage incentives provided by programs such as Operation Warp Speed.

Many observers have noted that COVID-19 vaccines have been developed at an unprecedented speed with progress across stages measured in months rather than years. However, even months of delays have considerable implications for the control of the pandemic, and there has been substantial heterogeneity across vaccine candidates in how fast they have progressed to and through clinical trials.

We are interested to compare the progress of COVID-19 vaccines according to the public/private status and the location of their lead sponsor. Our interest in the location of the lead sponsor stems from the fact that innovator faced different early-stage incentives depending the on country-level actions taken by the respective governments to promote innovation. For instance, support from the Operation Warp Speed was more readily available to American companies. However, vaccine developers faced a single global market, as a successful vaccine could be sold globally_especially in the initial stages of the pandemic due to limited supplies of the doses. Thus, in the context, we may see the late-stage market size incentives as essentially uniform across vaccine developers, while the early-stage incentives varied by country location. ${ }^{39}$

Our analysis is based on various vintages of the WHO vaccine landscapes supplemented by hand curated data on COVID-19 vaccine developers and their location. We first analyze how many months it took for a COVID-19 vaccine candidate to enter the preclinical stage, conditional on entering the preclinical stage by the end of 2020. Then, controlling for when the vaccine entered the preclinical stage, we look at whether a COVID19 vaccine candidate entered clinical trial before the end of 2020, and the number of phases a COVID-19 vaccine candidate went through by the end of $2020 .{ }^{40}$ In all cases, our variables of interest are the public/private status of the vaccine lead sponsor(s), and the location of the lead sponsor (U.S., Europe, China, and rest of the world). We control for the technology type (mRNA, viral vector, protein subunit, attenuated, etc.) in all specifications.

(insert Table 4 about here )

Results are shown in Table 4. We have a total 222 COVID-19 vaccine candidates which took on average six months to enter the preclinical stage. A quarter of these candidates had entered clinical trials by the end

\footnotetext{
${ }^{39}$ Note that under OWS, the purchase price paid for vaccine doses were below market price.

${ }^{40} \mathrm{We}$ code the number of phases as 1 for vaccines in phase 1 by the end of 2020, 1.5 for vaccines in phase $1 / 2,2$ for vaccines in phase 2, 2.5 for vaccines in phase 2/3, 3 for vaccines in phase 3, and 4 for the two vaccines approved in the U.S. by the end of 2020 .
} 
of 2020. We find that COVID-19 vaccines with a private lead sponsor, or involving a collaboration between a public and private lead sponsor, moved to the preclinical stage 2 months earlier than those with a public lead sponsor. However, there is little difference between these sponsor types in the propensity to enter clinical trials or the number of phases completed by the end of December 2020.

Compared to European vaccine candidates, U.S. vaccine candidates moved faster to the preclinical stage, and were more likely to enter clinical trials. Chinese vaccine candidate were also faster than European vaccine candidates in moving to preclinical stage and entered clinical trials at a higher rates. Since market size-a late-stage incentive-is largely uniform across regions, these cross-country variations in speed of vaccine $R \& D$ effort are likely to reflect national differences in early-stage incentives, including the fact that Operation Warp Speed did not have a European equivalent.

\section{Conclusion}

In this paper, we study the global R\&D effort to fight the deadliest diseases to examine the drivers of innovation. We present four main results. First, we find that global pharmaceutical R\&D activity-measured by clinical trials - typically follows the 'law of diminishing effort': i.e. the elasticity of R\&D effort with respect to market size is about $1 / 2$ in the cross-section of diseases. Second, the R\&D response to COVID-19 has been a major exception to this law, with the number of COVID-19 trials being 7 to 20 times greater than that implied by its market size. Third, the aggregate elasticity of science and innovation can be very large, as demonstrated by aggregate flow of clinical trials rising by $38 \%$ in 2020, with limited crowding out of trials for non-COVID diseases. And fourth, public institutions and government-led incentives were a key driver of the COVID19 R\&D effort-with public research institutions accounting for 70 percent of all COVID-19 clinical trials globally and being 10 percentage points more likely to conduct a COVID-19 trial relative to private firms.

While we emphasize the potential role of public institutions, the private sector is possibly more efficient at some stages of the development and commercialization process. For instance, we find that private companies were faster than public research institutions in moving to the pre-clinical stage for COVID-19 vaccines. Thus, harnessing the innovation potential of public research institution may need to be complemented by engaging the private sector with appropriate incentives, and over time closing the gap in efficiency between the two.

Various observers have long worried that scaling up innovation is difficult either due to scarcity of good ideas/talent and a corresponding decline in research productivity (Bloom et al. 2020), or due to an inherent lack of private incentives to pursue such effort (Kremer 2001). However, despite these barriers, the unprecedented global $R \& D$ response to fight COVID-19 shows that the aggregate innovation effort may be operating signif- 
icantly below its potential. Indeed, the innovation actors managed to increase the aggregate $R \& D$ effort (as measured by clinical trials) by $38 \%$ in 2020 , and deliver several successful vaccine candidates about 10 times faster than previous efforts for other diseases. (This corresponds to a very large aggregate short-term $R \& D$ elasticity with respect to changes market size of at least 0.6 , and potentially much higher.) At the same time, this was done without significantly sacrificing $R \& D$ effort for other deadly diseases.

One may be tempted to attribute the exceptionalism of COVID-19 R\&D to the relative "easiness" of finding cures for the disease, such that its biology was relatively more amenable to a quick technological breakthrough. However, this would be in stark contrast to the consensus view of experts at the beginning of the pandemic. At the outbreak of COVID-19, the world still did not have any vaccines or effective treatments for the other known coronaviruses even after decades of work, and nearly no experts anticipated having a licensed COVID19 vaccine before mid-2021. Alternatively, the large scale of the COVID-19 effort may also partly reflect the fact that it is a new disease. New diseases may elicit a differential R\&D response, either because the stock of promising ideas to explore has not been depleted by previous effort, or because drugs for a new disease do not face competition from previously invented drugs. It is difficult to ascertain this possibility empirically given that new diseases, especially of this severity, are rare.

We hope future research can examine three areas that remain beyond the scope of this paper. First, the extent to which our results can generalize beyond the pharmaceutical sector is an open question. The need to scale up innovation in domains such as clean energies and climate mitigation technologies is abundantly clear. Yet the type of the R\&D problems, and the nature of $R \& D$ effort to solve them is certainly different. One idiosyncratic factor that may have contributed to the scale of the COVID-19 R\&D response is the existence of a large pool of human capital due to earlier policy interventions, such as the doubling of NIH R\&D funding in the 2000s.

Second, there remains scope for future research to evaluate the quality of COVID-19 R\&D. While we attempt to address this question in a limited way by studying the progression of clinical trials for COVID19 vaccines through different stages, it is too early for us to conduct a comprehensive assessment of quality of $R \& D$. There are various reasons why average quality of $R \& D$ may have been impacted, including due to accelerated decision making by regulators and researchers, sheer need for speed more generally due to the large social costs associated with the pandemic, or researchers switching to study domains that are beyond their narrow areas of expertise. At the same time, COVID-19 brought together individuals from different domains to collaborate that could have opened the door for more creative ways to evaluate hard scientific problems.

Third, we hope that our work encourages further research in understanding the role of non-monetary in- 
centives and early-stage incentives as drivers of innovation. There is an intuitive understanding among many that reputational concerns, altruism, the sense of duty to the greater good, and space for creativity and curiosity facilitated by unconditional funding may play an important role in innovation. In this context, there is scope for future research to empirically evaluate the importance of these factors in different innovation domains.

In summary, the COVID-19 R\&D response raises the distinct possibility that global pharmaceutical innovation in the future can be scaled up significantly. However, while economists are naturally in favor of market size as a driving force for innovation, our work suggests taking a broader perspective on what drives innovation. In particular, in order to scale up global innovation to promote the greater good, policymakers/philanthropists might want to complement the market size effect with early-stage incentives that harness the power public research institutions and non-monetary incentives. 


\section{References}

Abi Younes, G., Ayoubi, C., Ballester, O., Cristelli, G., de Rassenfosse, G., Foray, D., Gaule, P, Pellegrino, G, van den Heuvel, M, Webster, E \& Zhou, L. (2020). COVID-19: Insights from innovation economists. Science and Public Policy.

Acemoglu, D. (2003). Why not a political Coase theorem? Social conflict, commitment, and politics. Journal of Comparative Economics. 31(4): 620-652.

Acemoglu, D., \& Linn, J. (2004). Market Size in Innovation: Theory and Evidence From the Pharmaceutical Industry. The Quarterly Journal of Economics. 119(3):1049-1090.

Aghion, P., and Howitt, P. (1992). “A Model of Growth through Creative Destruction,” Econometrica, $323-351$.

Ahuja, A., Athey, S., Baker, A., Budish, E., Castillo, J.C., Glennerster, R. , Kominers, S.D., Kremer, M., Lee, J., Prendergast, C., Snyder, C.M., Tabarrok, A., Tan, B. J. \& Wiecek W. (2021) Preparing for a Pandemic: Accelerating Vaccine Availability. BFI Working Paper 2021-008w, 96(2), 103-107.

Arrow, K. (1962). Economic Welfare and the Allocation of Resources for Invention. In The Rate and Direction of Inventive Activity: Economic and Social Factors (pp. 609-626). Princeton University Press.

Asplund, M. (2002). Risk-averse firms in oligopoly. International Journal of Industrial Organization, 20(7): 995-1012.

Athey, S., Kremer, M., Snyder, C. M., \& Tabarrok, A. (2020) In the Race for a Coronavirus Vaccine, We Must Go Big. Really, Really Big. New York Times May 4.

Azoulay, P., \& Jones, B. (2020). Beat COVID-19 through innovation. Science, 268(6491): 553

Azoulay, P., Graff Zivin, J. S., Li, D., \& Sampat, B. N. (2019). Public R\&D investments and private-sector patenting: evidence from NIH funding rules. The Review of Economic Studies, 86(1): 117-152.

Ball, P. (2021). The lightning-fast quest for COVID vaccines-and what it means for other diseases. Nature. 589(7840):16-18

Begum, J., Mir, N. A., Dev, K., Buyamayum, B., Wani, M. Y., \& Raza, M. (2020). Challenges and prospects of COVID-19 vaccine development based on the progress made in SARS and MERS vaccine development. Transboundary and Emerging Diseases. 00:1-14

Bloom, N., Jones, C. I., Van Reenen, J., \& Webb, M. (2020). Are ideas getting harder to find?. American 
Economic Review. 110(4): 1104-44.

Bloom, N., Van Reenen, J., \& Williams, H. (2019). A toolkit of policies to promote innovation. Journal of Economic Perspectives. 33(3): 163-84.

Blume-Kohout, M. E., \& Sood, N. (2013). Market size and innovation: Effects of Medicare Part D on pharmaceutical research and development. Journal of Public Economics. 97: 327-336.

Bryan, K. A., Lemus, J. \& Marshall, G. (2020). Innovation During a Crisis: Evidence from Covid-19. Mimeo, University of Toronto

Budish, E., Roin, B. N., \& Williams, H. (2015). Do firms underinvest in long-term research? Evidence from cancer clinical trials. American Economic Review. 105(7): 2044-85.

Civan, A. \& Maloney, M. (2009). The Effect of Price on Pharmaceutical R\&D.” The B.E. Journal of Economic Analysis \& Policy. 9:1-24.

Chalkidou, K., Kettler, H., Ramakrishnan, G, Silverman, R \& Towse, A. (2020). Leave No One Behind: Using a Benefit-Based Advance Market Commitment to Incentivise Development and Global Supply of COVID-19 Vaccines. Center for Global Development note, Washington DC.

Clemens, J., \& Olsen, M. (2021) Medicare and the Rise of American Medical Patenting: The Economics of User-Driven Innovation. Mimeo, the University of Copenhagen.

Clemens, J., \& Rogers, P. (2020). Demand shocks, procurement policies, and the nature of medical innovation: Evidence from wartime prosthetic device patents. NBER Working Paper no 26679. National Bureau of Economic Research.

ClinicalTrials.gov [Internet]. Bethesda (MD): National Library of Medicine. Available from http://clinicatrials.gov

Dranove, D., Garthwaite, C., \& Hermosilla, M. (2014). Pharmaceutical profits and the social value of innovation. NBER Working Paper No 20212. National Bureau of Economic Research.

Dubois, P., De Mouzon, O., Scott-Morton, F., \& Seabright, P. (2015). Market size and pharmaceutical innovation. The RAND Journal of Economics. 46(4): 844-871.

Dusetzina, S. (2016) Drug pricing trends for orally administered anticancer medications reimbursed by commercial health plans, 2000-2014. JAMA Oncology 2:960-961.

Finkelstein, A. (2004). Static and dynamic effects of health policy: Evidence from the vaccine industry. The Quarterly Journal of Economics. 119(2): 527-564. 
Giaccotto, C., Santerre, R.E., \& Vernon, J.A. (2005) Drug Prices and Research and Development Investment Behavior in the Pharmaceutical Industry. Journal of Law and Economics, 48:195-214.

Golec, J., Hegde, S., \& Vernon, J. A. (2010). Pharmaceutical R\&D spending and threats of price regulation. Journal of Financial and Quantitative Analysis. 45(1):239-264.

GBD 2015 Mortality and Causes of Death Collaborators (2016) Global, regional, and national life expectancy, all-cause mortality, and cause-specific mortality for 249 causes of death, 1980 to 2015: a systematic analysis for the Global Burden of Disease Study 2015. The Lancet. 388: 1459-1544

Global Burden of Disease Collaborative Network. Global Burden of Disease Study 2017 (GBD 2017) Results. Seattle, United States: Institute for Health Metrics and Evaluation (IHME), 2018. Available from http://ghdx.healthdata.org/gbd-results-tool.

Gross, D. P., \& Sampat, B. N. (2021). The Economics of Crisis Innovation Policy: A Historical Perspective. NBER Working Paper 28335. National Bureau of Economic Research.

Higgins, M. J., \& Rodriguez, D. (2006). The outsourcing of R\&D through acquisitions in the pharmaceutical industry. Journal of Financial Economics. 80(2): 351-383.

Kao, J. (2019). Charted Territory: Evidence from Mapping the Cancer Genome and R\&D Decisions in the Pharmaceutical Industry. Mimeo, UCLA

Koijen, R. S., Philipson, T. J., \& Uhlig, H. (2016). Financial health economics. Econometrica. 84(1): 195-242.

Kremer, M. (2000). Creating markets for new vaccines. Part I: rationale. Innovation Policy and the Economy. 1: 35-72.

Kremer, M. (2002). Pharmaceuticals and the developing world. Journal of Economic Perspectives. 16(4): $67-90$.

Kremer, M., \& Glennerster, R. (2004). Strong medicine: creating incentives for pharmaceutical research on neglected diseases. Princeton University Press.

Kremer, M., \& Williams, H. (2010). Incentivizing innovation: Adding to the tool kit. Innovation Policy and the Economy. 10(1): 1-17.

Kremer, M., \& Snyder, C. M. (2015). Preventives versus treatments. The Quarterly Journal of Economics. 130(3): 1167-1239.

Kremer, M., Levin, M., \& Snyder, C.M. (2020). Advance Market Commitments: Insights from Theory and 
Experience. AEA Papers and Proceedings. 110:269-73.

Krieger, J., Li, X., \& Thakor, R. T. (2018). Find and replace: R\&D investment following the erosion of existing products. Available at SSRN 3240344

Kyle, M. K., \& McGahan, A. M. (2012). Investments in pharmaceuticals before and after TRIPS. Review of Economics and Statistics. 94(4): 1157-:1172.

Mahlich, J. C., \& Roediger-Schluga, T. (2006). The determinants of pharmaceutical R\&D expenditures: evidence from Japan. Review of Industrial Organization. 28(2): 145-164.

Maurer, S. M. (2006). Choosing the right incentive strategy for research and development in neglected diseases. Bulletin of the World Health Organization. 84(5): 376-381.

Moran, M. (2005). A breakthrough in R\&D for neglected diseases: new ways to get the drugs we need. PLoS Medicine. 2(9): e302

Muñoz, V., Visentin, F., Foray, D., \& Gaule, P. (2015). Can medical products be developed on a non-profit basis? Exploring product development partnerships for neglected diseases. Science and Public Policy. 42(3): $315-338$

Le, T. T., Cramer, J. P., Chen, R., \& Mayhew, S. (2020). Evolution of the COVID-19 vaccine development landscape. Nature Reviews Drug Discovery. 19(10): 667-8.

Lichtenberg, F. R. (2007). Importation and innovation. Economics of Innovation and New Technology, 16(6), 403-417.

Lichtenberg, F. R., \& Waldfogel, J. (2003). Does Misery Love Company? Evidence from pharmaceutical markets before and after the Orphan Drug Act. NBER Working Paper 9750. National Bureau of Economic Research.

Lovallo, D., Koller, T., Uhlaner, R., \& Kahneman, D. (2020). Your Company is Too Risk Averse. Harvard Business Review. 98(2): 104-111.

Mazzucato, M. (2013). The Entrepreneurial State: Debunking Public vs. Private Sector Myths

Myers, K. (2020). The Elasticity of Science. American Economic Journal: Applied Economics, 12(4), 103-34.

Myers, K., Tham, W. Y., Yin, Y., Cohodes, N., Thursby, J. G., Thursby, M., Schiffer, P.E., Walsh, J.T., Lakhani, K.R. \& Wang, D. (2020). Quantifying the Immediate Effects of the COVID-19 Pandemic on Scientists. Available at SSRN 3608302. 
NIHR (2020) First drug to reduce mortality in hospitalised patients with respiratory complications of COVID-19 found. Published June 16 2020. https://www.nihr.ac.uk/news/first-drug-to-reduce-mortality-inhospitalised-patients-with-respiratory-complications-of-covid-19-found/25061

Olson, M. K., \& Yin, N. (2018). Examining firm responses to R\&D policy: An analysis of pediatric exclusivity. American Journal of Health Economics. 4(3): 321-357.

Perez-Saez, F.J., Lauer, S.A., Kaiser, L., Regard, S., Delaporte, E., Guessous, I., Sringhini, S., Azman, A.S. (2020) Serology-informed estimates of SARS-CoV-2 infection fatality risk in Geneva, Switzerland. Lancet Infectious Diseases. 3099(20):30584-3

Qian, Y. (2007). Do National Patent Laws Stimulate Domestic Innovation in a Global Patenting Environment? A Cross-Country Analysis of Pharmaceutical Patent Protection, 1978-2002. The Review of Economics and Statistics 89(3), 436-45

Randolph, H. E., \& Barreiro, L. B. (2020). Herd Immunity: Understanding COVID-19. Immunity, 52(5): 737-741.

Roth, G. A., Abate, D., Abate, K. H., Abay, S. M., Abbafati, C., Abbasi, N., ... \& Abdollahpour, I. (2018). Global, regional, and national age-sex-specific mortality for 282 causes of death in 195 countries and territories, 1980-2017: a systematic analysis for the Global Burden of Disease Study 2017. The Lancet, 392: 1736-1788.

Pillaiyar, T., Meenakshisundaram, S., \& Manickam, M. (2020). Recent discovery and development of inhibitors targeting coronaviruses. Drug Discovery Today 25(4): 668-688.

Saif, L. J. (2020). Vaccines for COVID-19: Perspectives, prospects, and challenges based on candidate SARS, MERS, and animal coronavirus vaccines. European Medical Journal

Scotchmer, S. (2004). Innovation and incentives. MIT press.

Snyder, C. M., Hoyt, K., Gouglas, D., Johnston, T., \& Robinson, J. (2020). Designing Pull Funding For A COVID-19 Vaccine: Article proposes a "pull" program that incentivizes late-stage development and manufacturing of COVID-19 vaccines by awarding advance purchase commitments to bidding firms. Health Affairs. 39(9), 1633-1642.

Stringhini, S., Wisniak, A., Piumatti, G., Azman, A.S., Lauer, S.A., Baysson, H., ..., \& Guessous I. (2020) Seroprevalence of anti-SARS-CoV-2 IgG antibodies in Geneva, Switzerland (SEROCoV-POP): a populationbased study. The Lancet. 396:313-319

Verity, R., Okell, L. C., Dorigatti, I., Winskill, P., Whittaker, C., Imai, N., Dighe, A., ..., \& Ferguson, N. 
(2020). Estimates of the severity of coronavirus disease 2019: a model-based analysis. The Lancet Infectious Diseases. 20(6):669-677

Ward, M. R., \& Dranove, D. (1995). The Vertical Chain of Research and Development in the Pharmaceutical Industry. Economic Inquiry, 33(1), 70-87

Wighton K \& van Elsland S L. (2020) Coronavirus fatality rate estimated by Imperial scientists. Feb 11, 2020. https://www.imperial.ac.uk/news/195217/coronavirus-fatality-rate-estimated-imperial-scientists

World Health Organization (2020) DRAFT landscape of COVID-19 candidate vaccines. updated 29 October 2020 .

Wu, J. T., Leung, K., Bushman, M., Kishore, N., Niehus, R., de Salazar, P. M., ... \& Leung, G. M. (2020). Estimating clinical severity of COVID-19 from the transmission dynamics in Wuhan, China. Nature Medicine, 26(4), 506-510.

Yin, W. (2008). Market incentives and pharmaceutical innovation. Journal of Health Economics, 27(4), 1060-1077. 


\section{Tables and Figures}

Figure 1: R\&D Effort across Diseases and the Law of Diminishing Effort
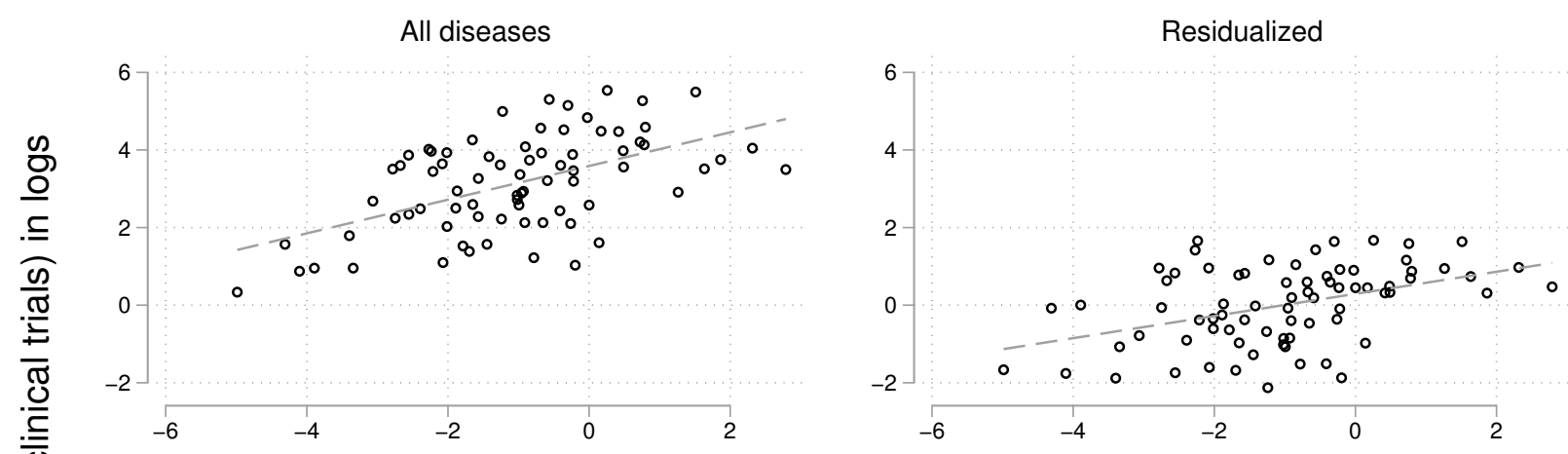

\section{Cancers}

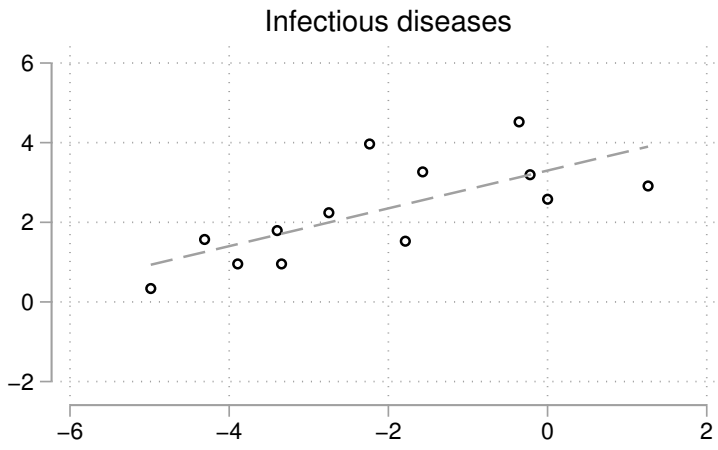

\section{Market size (trillion USD) in logs}

Notes: The figure displays the relationship between potential market size and research effort in the cross-section of 75 diseases in our sample (COVID-19 not included). The empirical regularity that the slope of the linear fit (measuring the elasticity of research effort to potential market size) is significantly below one is what we call the 'law of diminishing effort'. Research effort is defined as the average yearly number of new trials per disease from 2015 to 2019, and expressed in logs. Potential market size is the 2017 disease-level mortality at the national level weighted by national GDP per capita and a value of statistical life of USD 1 million for the mean global citizen, expressed in logs. The upper left figure displays the overall relationship, while the lower left, and lower right figure restrict the sample to cancers and infectious diseases respectively. Finally, the upper right figure displays residualized research effort instead of actual research effort, where the residualized research effort comes from a regression of research effort on a broad set of potential determinants (except potential market size) detailed in Table 1 column 4. The regression equivalent of these figures are in Table 1. 
Figure 2: Share of COVID-19 Trials among Newly Started Trials

\section{Share of new trials directed to COVID-19}

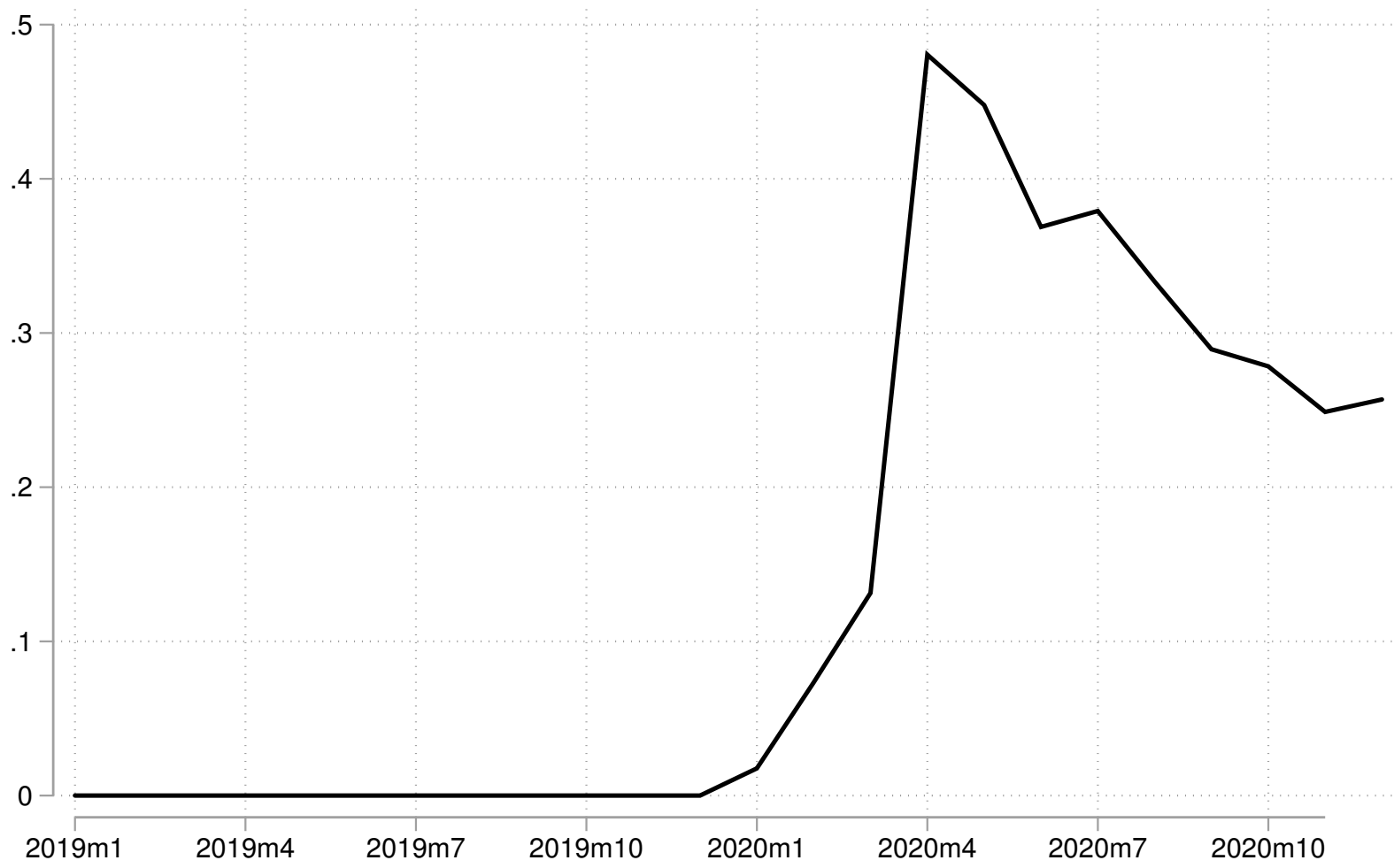

Notes: Based on clinicaltrials.gov data, the figure displays the share of new trials that were related to COVID-19 among all new trials on a monthly basis. For example, a number of .4 implies that $40 \%$ of the new trials in a given month were related to COVID-19. The COVID-19 trials are tagged as such by clinicaltrials.gov based upon a set of keywords related to COVID-19. 
Figure 3: New Clinical Trials Started Monthly for All Diseases

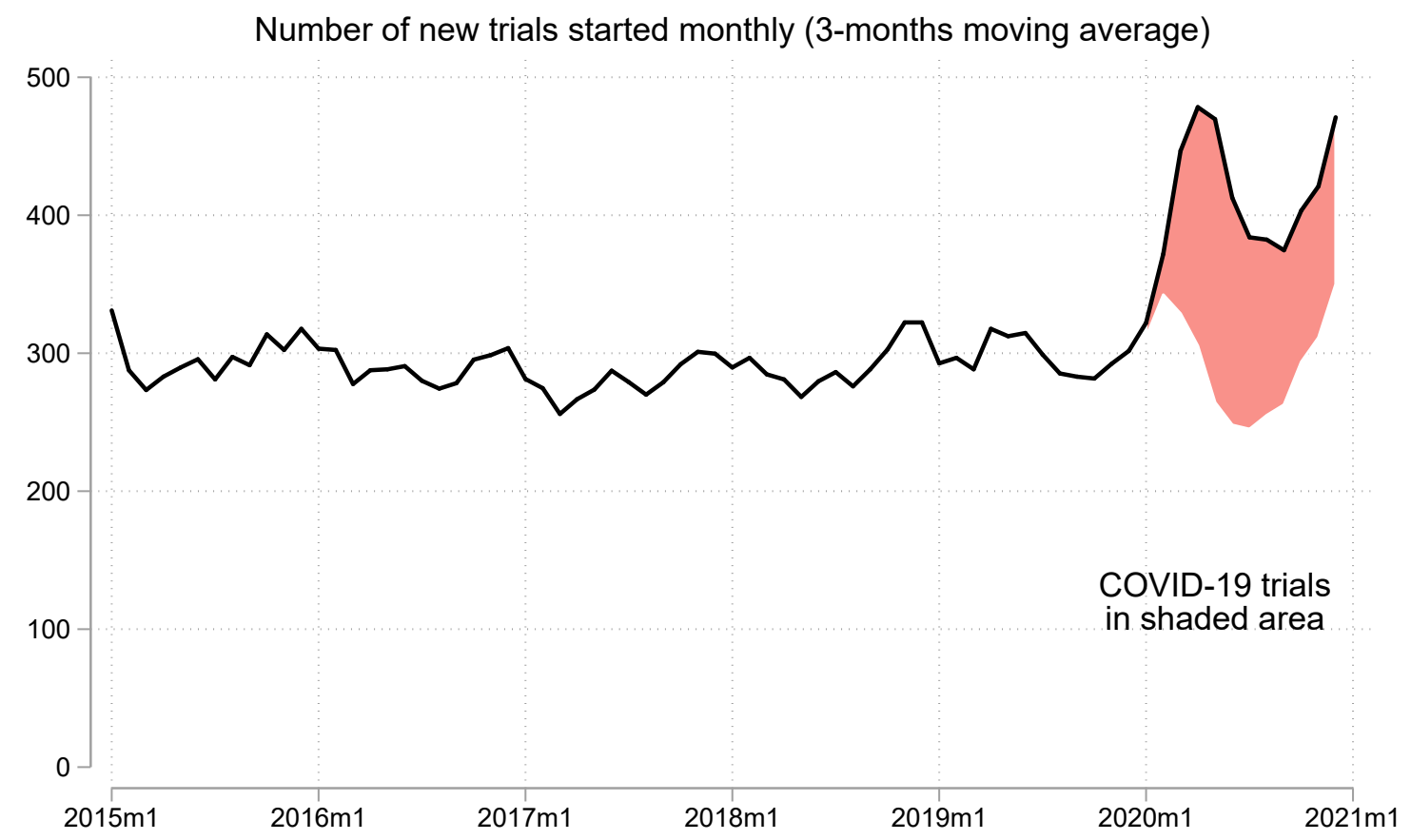

Notes: Based on clinicaltrials.gov data, the figure displays the total of new clinical trials worldwide (across all diseases) on a monthly basis. COVID-19 trials are showed in the shaded area. COVID-19 trials are tagged as such by clinicaltrials.gov based upon a set of keywords related to COVID-19. 
Figure 4: Crowding Out of R\&D Directed Towards Non-COVID-19 Diseases

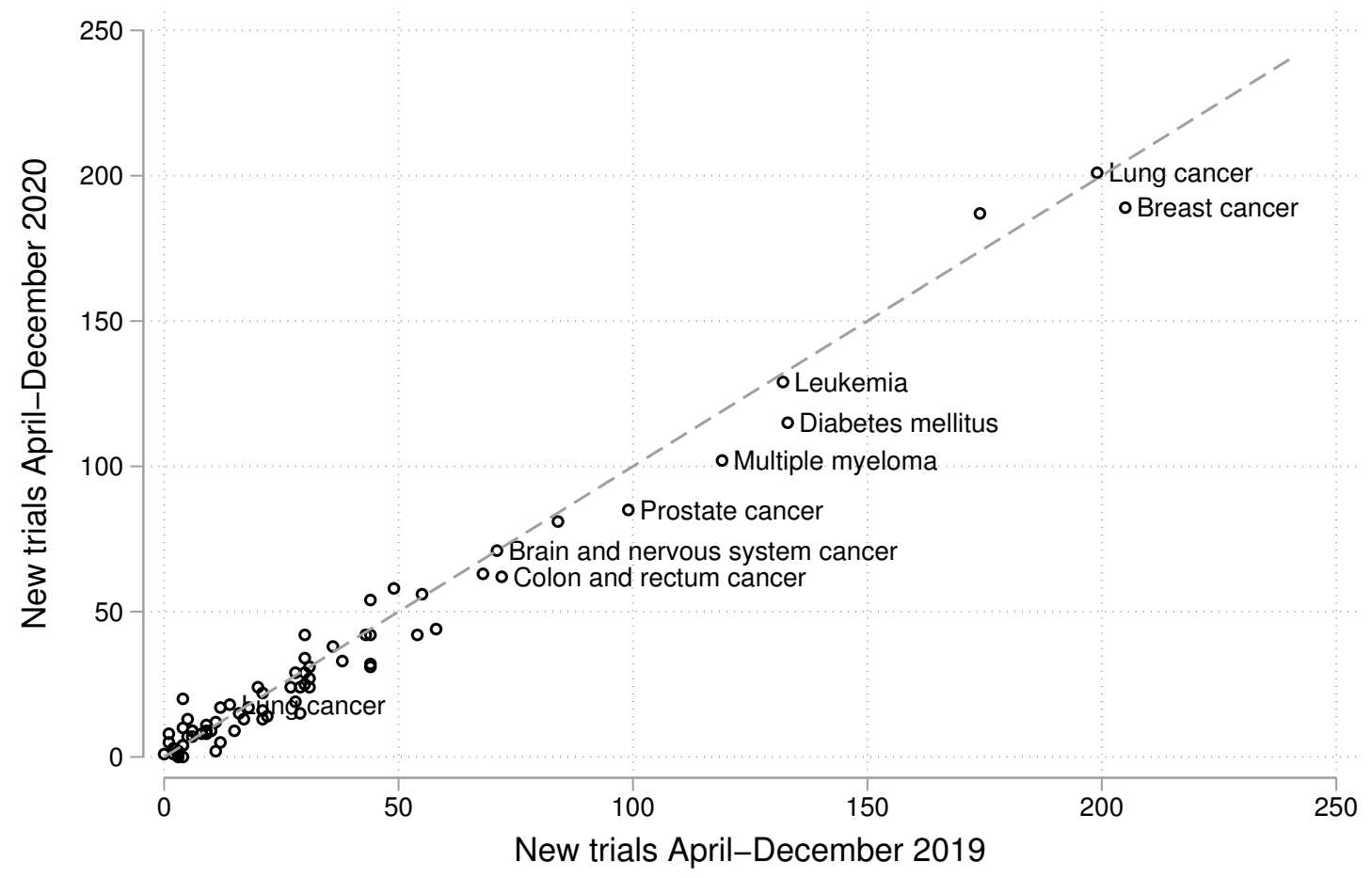

Notes: In this figure, we compare the number of new trials by disease between 2019 (April-December) and 2020 (April-December). The sample includes all diseases except COVID-19. The choice of using the last three quarters for our comparison window is based on the spike in COVID-19 clinical trials observed after Q1 of 2020. 
Figure 5: Actual vs. Expected Number of COVID-19 Trials Based on its Potential Market Size

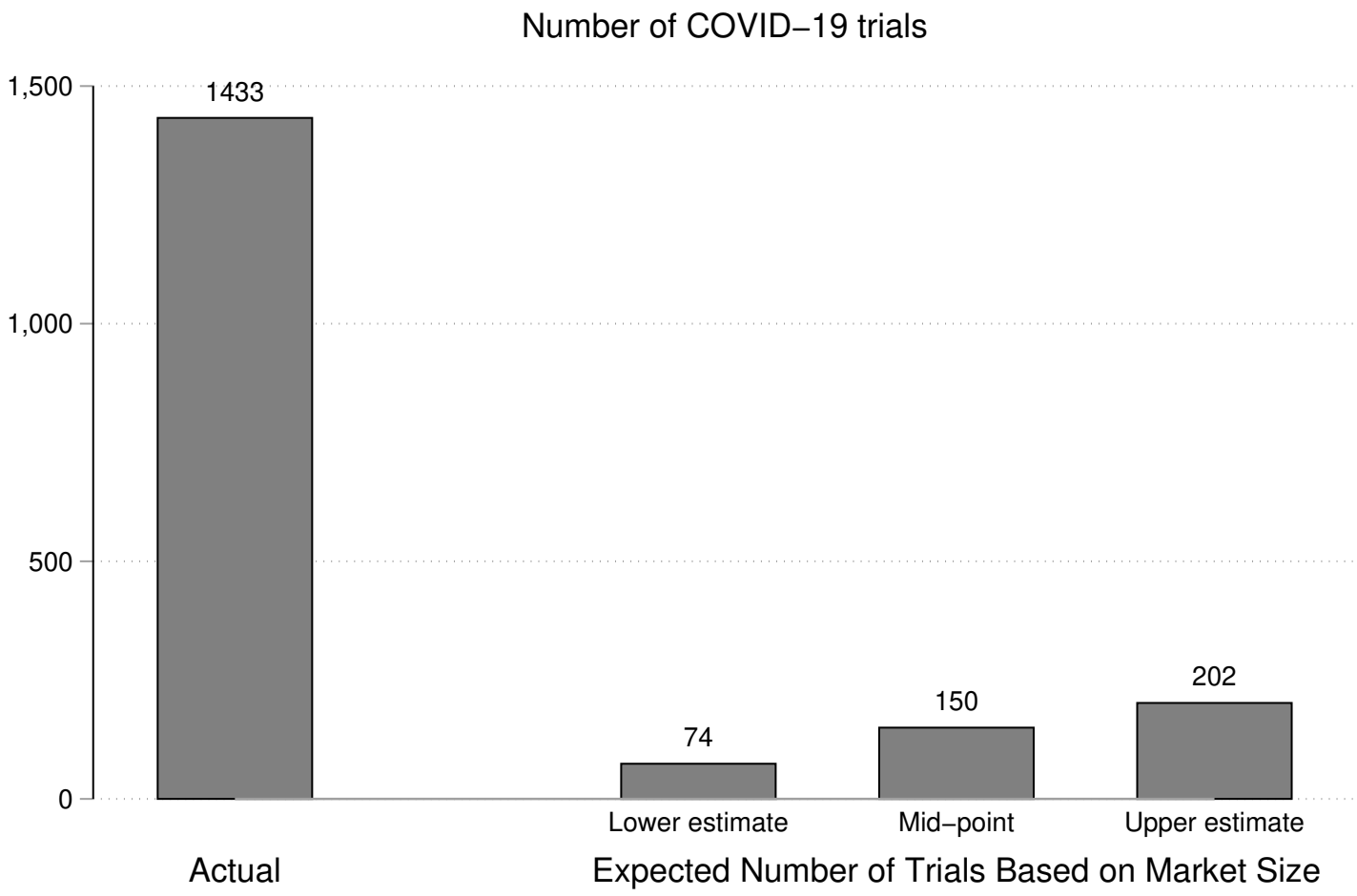

Notes: The figure displays the actual number of COVID-19 trials (left) and the expected number of (right) based on potential market size under different scenarios (right). To derive the expected number of COVID-19 trials based on potential market size, we combine an estimate of (a) the relationship between research effort and (b) potential market size with an estimate of the COVID-19 potential market size. The computation of (a) is based a regression of log research effort on log market size, which yields a point estimate of 0.43 (See Table 1 column 1). For (b), we quantify the likely death burden of COVID-19 in the hypothetical case in which in the absence of non-pharmaceutical control measures $70 \%$ of the world population eventually would get infected. The $70 \%$ accounts for the typical herd immunity estimates, whereby if the disease were allowed to spread, due to herd immunity the number of cases would fall after a certain threshold, thereby infecting only a fraction of the population. We quantify the death burden under three different scenarios (by varying infection fatality rates), which when combined with (a) gives us three different estimates of expected number of COVID-19 trials based on its market size. Based on this exercise, we find the actual number of COVID-19 trials is 7 to 20 times greater than that implied by its market size. To give a sense of the magnitude of the COVID-19 death burdens under the three different scenarios (5.3, 26.6, and 53.2 million), note that the global burden from all diseases combined has been about 50 million deaths per year in recent years. The largest non-COVID-19 disease in our sample is coronary heart disease, which has an annual death burden of about 9 million. So, another way to interpret the COVID-19 death burdens under the three different scenarios is that it ranges from 0.6 to 6 times the death burden of coronary heart disease for the purposes of our exercise. 
Figure 6: COVID-19 R\&D Effort Compared with Other Diseases

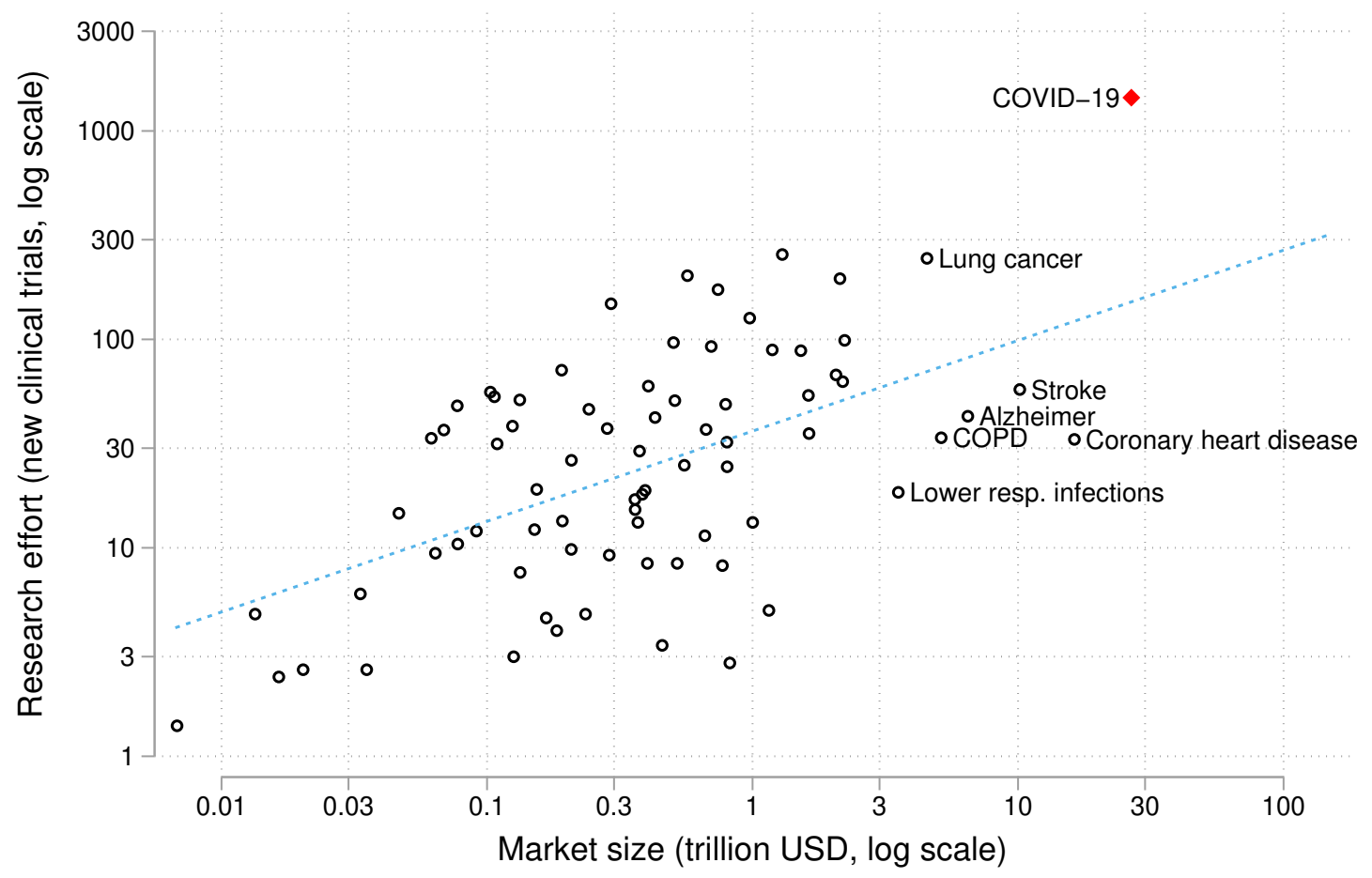

Notes: The figure displays the relationship between potential market size and research effort in the cross-section of 75 diseases in our sample, plus COVID-19. Research effort is defined as the average yearly number of new trials per disease from 2015 to 2019 ; for COVID-19 we use the actual number of 2020 COVID-19 trials instead. Potential market size is the 2017 disease-level mortality at the national level weighted by national GDP per capita and a value of statistical life of USD 1 million for the mean global citizen, expressed in logs. For COVID-19, our estimate of potential market size is based on the hypothetical case in which in the absence of non-pharmaceutical control measures $70 \%$ of the world population eventually would get infected, and COVID-19 has an infection fatality rate of $0.5 \%$. This corresponds to 26.6 million COVID-19 deaths, or the mid-point estimate in Figure 5. See main text for a detailed discussion of the COVID-19 potential market size. 
Table 1: R\&D Effort across Diseases and the Law of Diminishing Effort

\begin{tabular}{|c|c|c|c|c|}
\hline & (1) & (2) & (3) & (4) \\
\hline & \multicolumn{4}{|c|}{ Dependent variable $=$ New clinical trials $(\log )$} \\
\hline & All diseases & Cancers & Infectious diseases & All diseases \\
\hline Potential market size $(\log )$ & $\begin{array}{c}0.434^{* * *} \\
(0.074)\end{array}$ & $\begin{array}{c}0.613^{* * *} \\
(0.095)\end{array}$ & $\begin{array}{c}0.475^{* * *} \\
(0.127)\end{array}$ & $\begin{array}{c}0.364^{* * *} \\
(0.068)\end{array}$ \\
\hline DALYs over deaths & & & & $\begin{array}{c}0.002 \\
(0.001)\end{array}$ \\
\hline $\begin{array}{l}\text { Change in disease burden } \\
\text { (from } 2007 \text { to 2017) }\end{array}$ & & & & $\begin{array}{l}0.814^{* *} \\
(0.321)\end{array}$ \\
\hline $\begin{array}{l}\text { Share of disease burden } \\
\text { in high-income countries }\end{array}$ & & & & $\begin{array}{l}-0.951 \\
(1.057)\end{array}$ \\
\hline $\begin{array}{l}\text { Infectious } \\
\text { disease }\end{array}$ & & & & $\begin{array}{c}0.072 \\
(0.347)\end{array}$ \\
\hline Cancer & & & & $\begin{array}{c}0.925^{* * *} \\
(0.269)\end{array}$ \\
\hline Disease difficulty & & & & $\begin{array}{l}-0.180 \\
(0.121)\end{array}$ \\
\hline Observations & 75 & 27 & 13 & 75 \\
\hline R2 & 0.287 & 0.396 & 0.514 & 0.482 \\
\hline
\end{tabular}

Notes: The table investigates the relationship between potential market size and research effort in the cross-section of 75 diseases in our sample (COVID-19 not included). The empirical regularity that the slope of the linear fit (measuring the elasticity of research effort to potential market size) is significantly below one is what we call the 'law of diminishing effort'. The data is set up as a cross section of 75 diseases, with a disease being the unit of observation. Regressions shown in column 1 and 4 are estimated using the full sample; regressions in columns 2 and 3 are estimated using the subsample of cancers and infectious diseases respectively. The dependent variable is the average yearly number of new trials per disease from 2015 to 2019, expressed in logs. The variable of interest, potential market size, is the 2017 disease-level mortality at the national level weighted by national GDP per capita and a value of statistical life of USD 1 million for the mean global citizen, expressed in logs. As a measure of 'disease difficulty' in terms of R\&D we compute the ratio of phase III trials to phase I trials, roughly reflecting the share of drug candidates that progress to phase III from phase I. See main text for a description of the other control variables in column 4. Estimation is by OLS. Robust standard errors are reported in parentheses. ${ }^{*} p<0.1,{ }^{* *} p<0.05,{ }^{* * *} p<0.01$. 
Table 2: Crowding Out Results: Clinical Trials Directed Towards Non-COVID-19 Diseases

\begin{tabular}{lc}
\hline & $(1)$ \\
& D.V. $=$ New clinical trials \\
\hline COVID-19 Outbreak & $-0.055^{* *}$ \\
& $(0.023)$ \\
\hline Disease fixed effects & Yes \\
\hline Diseases & 75 \\
Observations & 150 \\
\hline
\end{tabular}

Notes: In this table, we compare the number of new trials by disease between 2019 (April-December) and 2020 (April-December). The sample includes all diseases except COVID-19. The dependent variable is the number of new clinical trials directed towards that disease in a period. The variable of interest is COVID-19 Outbreak which is an indicator variable that turns to 1 in the second period (which coincides with the COVID-19 pandemic). The specification includes disease fixed effects and is estimated by Poisson Quasi-Maximum Likelihood. Robust standard errors are reported in parentheses. ${ }^{*} p<0.1,{ }^{* *} p<0.05,{ }^{* * *} p<0.01$. 
Table 3: COVID-19 R\&D Effort and Sponsor Characteristics

\begin{tabular}{|c|c|c|}
\hline & $\begin{array}{c}(1) \\
\text { Any COVID-19 trial }\end{array}$ & $\begin{array}{c}(2) \\
\text { \# of COVID-19 trials }\end{array}$ \\
\hline \multicolumn{3}{|l|}{ Trial sponsor location } \\
\hline US & $\begin{array}{c}0.005 \\
(0.022)\end{array}$ & $\begin{array}{l}-0.123 \\
(0.196)\end{array}$ \\
\hline China & $\begin{array}{c}-0.105^{* * *} \\
(0.025)\end{array}$ & $\begin{array}{c}-0.886^{* * *} \\
(0.256)\end{array}$ \\
\hline ROW & $\begin{array}{c}0.082^{* * *} \\
(0.026)\end{array}$ & $\begin{array}{l}0.364^{*} \\
(0.190)\end{array}$ \\
\hline \multicolumn{3}{|l|}{ Europe omitted } \\
\hline Other variables of interest & & \\
\hline $\begin{array}{l}\text { Sponsor size } \\
(\log )\end{array}$ & $\begin{array}{c}0.143^{* * *} \\
(0.011)\end{array}$ & $\begin{array}{c}0.700^{* * *} \\
(0.048)\end{array}$ \\
\hline $\begin{array}{l}\text { Prior experience with } \\
\text { respiratory diseases }\end{array}$ & $\begin{array}{c}0.272^{* * *} \\
(0.044)\end{array}$ & $\begin{array}{c}0.956^{* * *} \\
(0.175)\end{array}$ \\
\hline Private sponsor & $\begin{array}{c}-0.101^{* * *} \\
(0.017)\end{array}$ & $\begin{array}{c}-0.710^{* * *} \\
(0.134)\end{array}$ \\
\hline Observations & 1,773 & 1,773 \\
\hline Mean of dep. variable & 0.196 & 0.408 \\
\hline
\end{tabular}

Notes: In this table, we examine which type of sponsors had the strongest R\&D response to COVID-19. The term 'sponsor' refers to any research entity (e.g. hospitals, firms, etc.) that are listed as a 'sponsor' on the NIH clinical trials registry. Here, the sample is a cross-section of all sponsors that conducted two or more clinical trials from 2015 to 2019. We use as dependent variable either an indicator variable taking value one if the firm started at least one COVID-19 clinical trial (column 1), or the number of COVID-19 clinical trials started by the firm (column 2). The key variables of interest are the location of the trial sponsor, size of the sponsor, whether the sponsor was a private or a for-profit entity, and whether the sponsor had prior experience with R\&D directed towards respiratory diseases. We code the location of a sponsor based on the location of its clinical trials, and complemented the reported location with manual checks. The location category 'Europe' includes European Union Members as well as the United Kingdom and Switzerland. Sponsor size refers to the number of trials undertaken by the sponsor from 2015 to 2019 and enters the regression in log form. Prior experience with respiratory diseases is an indicator variable that takes value one if the firm has conducted at least one trial related to lower respiratory or upper respiratory infections from 2015 to 2019 . Private sponsor is an indicator variable taking value one if the sponsor is tagged as 'Industry' in the clinicaltrials.gov data. Column 1 is estimated using OLS, and column 2 using a Poisson regression. Robust standard errors are reported in parentheses. ${ }^{*} p<0.1,{ }^{* *} p<0.05,{ }^{* * *} p<0.01$. 
Table 4: Speed \& Success of COVID-19 Vaccine R\&D Effort

\begin{tabular}{|c|c|c|c|}
\hline & $\begin{array}{c}\text { (1) } \\
\text { Months to } \\
\text { preclinical }\end{array}$ & $\begin{array}{l}\quad(2) \\
\text { Entered clinical } \\
\text { trials }(0 / 1)\end{array}$ & $\begin{array}{c}(3) \\
\text { Nr of phase } \\
\text { progressions }\end{array}$ \\
\hline \multicolumn{4}{|l|}{ Vaccine developer location } \\
\hline U.S. & $\begin{array}{c}-1.189^{* *} \\
(0.602)\end{array}$ & $\begin{array}{l}0.163^{*} \\
(0.097)\end{array}$ & $\begin{array}{c}0.406 \\
(0.459)\end{array}$ \\
\hline China & $\begin{array}{l}-1.462^{*} \\
(0.757)\end{array}$ & $\begin{array}{l}0.341^{* *} \\
(0.140)\end{array}$ & $\begin{array}{l}1.074^{* *} \\
(0.530)\end{array}$ \\
\hline Rest of the World & $\begin{array}{c}-0.302 \\
(0.502)\end{array}$ & $\begin{array}{c}0.037 \\
(0.065)\end{array}$ & $\begin{array}{c}0.065 \\
(0.402)\end{array}$ \\
\hline \multicolumn{4}{|l|}{ Europe: omitted category } \\
\hline \multicolumn{4}{|l|}{ Vaccine developer status } \\
\hline $\begin{array}{l}\text { Private } \\
\text { Organization }\end{array}$ & $\begin{array}{c}-1.908^{* * *} \\
(0.427)\end{array}$ & $\begin{array}{c}0.057 \\
(0.069)\end{array}$ & $\begin{array}{c}0.294 \\
(0.252)\end{array}$ \\
\hline $\begin{array}{l}\text { Public-Private } \\
\text { Collaboration }\end{array}$ & $\begin{array}{c}-1.986^{* * *} \\
(0.516)\end{array}$ & $\begin{array}{l}-0.073 \\
(0.075)\end{array}$ & $\begin{array}{l}-0.091 \\
(0.394)\end{array}$ \\
\hline \multicolumn{4}{|l|}{ Control } \\
\hline Preclinical Month & & $\begin{array}{l}-0.015 \\
(0.012)\end{array}$ & $\begin{array}{c}-0.141^{* *} \\
(0.058)\end{array}$ \\
\hline Observations & 222 & 222 & 222 \\
\hline Mean of dep. var. & 6.050 & 0.252 & 0.422 \\
\hline
\end{tabular}

Notes: In this table, we examine the speed and success of COVID-19 vaccine development across the 222 COVID-19 vaccine candidates listed in the World Health Organization (WHO) COVID-19 candidate vaccine landscape database as of December 2020. The dependent variables are (a) the month in which the vaccine candidate first appeared as a pre-clinical candidate in the dataset (column 1), (b) an indicator variable that takes the value of one if the vaccine candidate entered clinical trials (column 2), and (c) number of phase progressions experienced by the vaccine candidate in the year 2020 (column 2). We code the number of phase progression as 1 for vaccines in phase 1 by the end of 2020, 1.5 for vaccines in phase 1/2, 2 for vaccines in phase 2, 2.5 for vaccines in phase $2 / 3,3$ for vaccines in phase 3, and 4 for the two vaccines approved in the U.S. by the end of 2020. The location of the lead developer was manually collected. The location category Europe includes European Union Members as well as the United Kingdom and Switzerland. Private sponsor is an indicator variable taking value one if the sponsor is tagged as 'Industry' in the clinicaltrials.gov data, whereas the Public-Private Collaboration takes the value of one when multiple sponsors are present with at least one industry sponsor and one nonindustry sponsor. Columns 1 and 2 are estimated using OLS, and Column 3 is estimated using a Poisson regression. Robust standard errors are reported in parentheses. ${ }^{*} p<0.1,{ }^{* *} p<0.05,{ }^{* * *} p<0.01$. 


\section{Appendix 1: Additional Figures and Tables}

Figure A1: Share of COVID-19 Trials among Newly Started Trials, by Region

Share of new trials directed to COVID-19
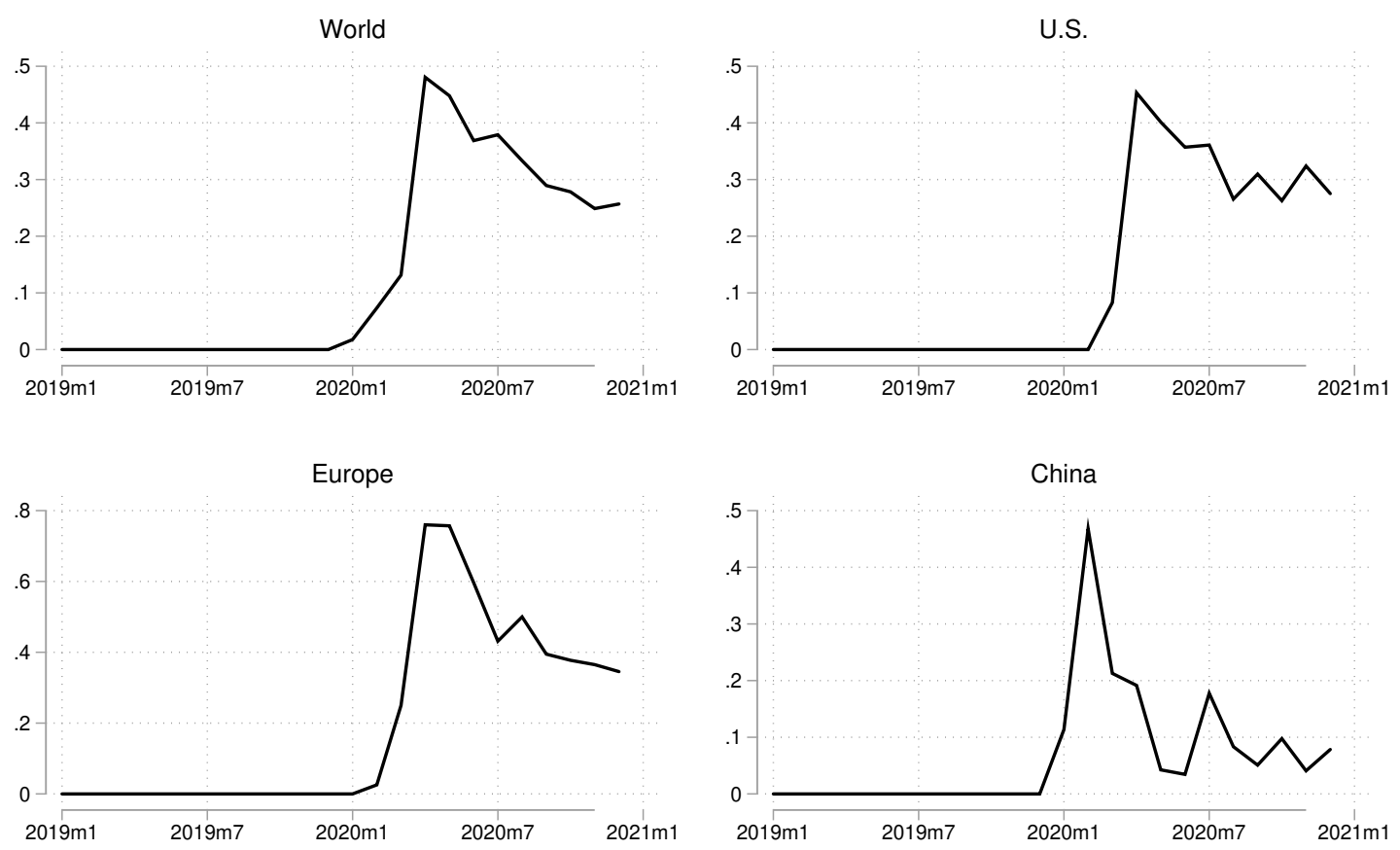

Notes: Based on clinicaltrials.gov data, the figure displays the share of new trials that were related to COVID-19 among all new trials on a monthly basis int he world, U.S., Europe, and China. Europe includes European Union Members as well as the United Kingdom and Switzerland. For example, a number of .4 implies that $40 \%$ of the new trials in a given month were related to COVID-19. The COVID-19 trials are tagged as such by clinicaltrials.gov based upon a set of keywords related to COVID-19. 
Figure A2: New Clinical Trials Started Monthly for All Diseases, by Region

Number of new trials started monthly by region (3-months moving average)
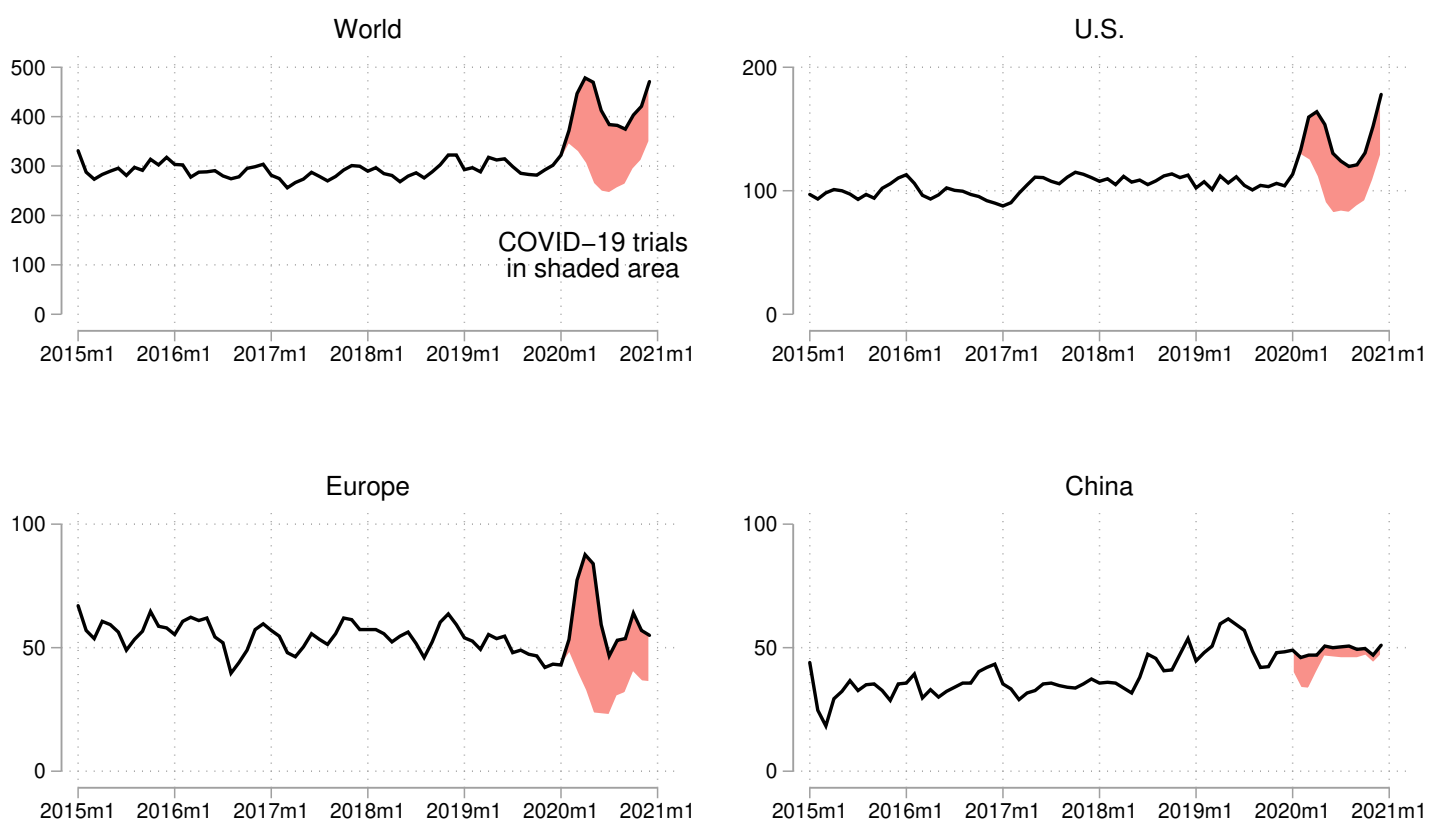

Notes: Based on clinicaltrials.gov data, the figure displays the total of new clinical trials (across all diseases) on a monthly basis in the world, U.S., Europe and China. Europe includes European Union Members as well as the United Kingdom and Switzerland. COVID19 trials are showed in the shaded area. COVID-19 trials are tagged as such by clinicaltrials.gov based upon a set of keywords related to COVID-19. 
Table A1: Descriptive statistics on disease cross-section $(\mathrm{n}=75)$

\begin{tabular}{lcccc}
\hline & Mean & S.D. & Min & Max \\
\hline Total trials from 2015 to 2019 & 45.0 & 54.92 & 1.40 & 253.80 \\
Deaths (millions) & 0.6 & 1.33 & 0.01 & 8.90 \\
Potential market size & 1.1 & 2.38 & 0.01 & 16.25 \\
DALYs (millions) & 21.9 & 36.11 & 0.31 & 185.49 \\
Change in mortality from 2007 to 2017 & 0.1 & 0.45 & -0.91 & 1.48 \\
Share of deaths in high-income countries & 0.3 & 0.18 & 0.00 & 0.73 \\
Infectious disease & 0.2 & 0.38 & 0.00 & 1.00 \\
Cancer & 0.4 & 0.48 & 0.00 & 1.00 \\
Ratio of Phase III to Phase 1 trials & 0.4 & 0.64 & 0.00 & 4.00 \\
\hline
\end{tabular}


Table A2: Elasticity of R\&D Effort to Market Size

\begin{tabular}{llll}
\hline Panel A: Literature (ordered by market size) & & & \\
& Measure of Market Size & Measure of R\&D Effort & Market \\
Paper & Global revenue of pharma. products & New molecular entities & Global for all diseases \\
\hline Dubois et al. (2015) & Number of cancer patients & Clinical trials & U.S. for cancer \\
Budish, Roin \& Williams (2015) & R\&D spending & Japan for all diseases \\
Mahlich \& Roediger-Schluga (2006) & Industry profit margin & Drugs in pipeline & U.S. for all diseases \\
Civan \& Maloney (2009) & Expected U.S. entry price & Chemotherapy regimens & U.S. for cancer \\
Lichtenberg (2007) & Numberr of cases & R\&D spending & U.S. for all diseases \\
Giacotto, Santerre, \& Vernon (2005) & Pharmaceutical price index & R\&D spending & U.S. for all diseases \\
Ward \& Dranove (1995) & Demand in a therapeutic area & & 0.53 \\
Acemoglu \& Linn (2004) & Income-weighted potential consumers & New molecular entities & U.S. for cancer \\
\hline Panel B: This paper & & & 0.58 \\
& & & \\
Table 1 Column 1 & & Global for all diseases \\
Table 1 Column 3 & Income-weighted potential consumers & Clinical trials & G-6 \\
Table 1 Column 2 & Income-weighted potential consumers & Clinical trials & Global for infectious diseases \\
\hline
\end{tabular}


Table A3: Descriptive statistics on COVID-19 vaccine candidates $(n=222)$

\begin{tabular}{lcccc}
\hline & Mean & S.D. & Min & Max \\
\hline Months to preclinical & 6.05 & 2.91 & 2.00 & 12.00 \\
Entered clinical trials (0/1) & 0.25 & 0.44 & 0.00 & 1.00 \\
Nr of phase progressions & 0.42 & 0.85 & 0.0 & 4.0 \\
& & & & \\
Vaccine developer location & & & & \\
\cline { 1 - 4 } U.S. & 0.20 & 0.40 & 0.00 & 1.00 \\
China & 0.09 & 0.29 & 0.00 & 1.00 \\
Europe & 0.25 & 0.43 & 0.00 & 1.00 \\
ROW & 0.45 & 0.50 & 0.00 & 1.00 \\
& & & & \\
Vaccine developer status & & & & \\
\cline { 1 - 4 } Private organization & 0.36 & 0.48 & 0.00 & 1.00 \\
Public-private collaboration & 0.16 & 0.37 & 0.00 & 1.00 \\
& & & & \\
Vaccine technology & & & & \\
\cline { 1 - 2 } DNA & 0.10 & 0.31 & 0.00 & 1.00 \\
Protein subunit & 0.35 & 0.48 & 0.00 & 1.00 \\
RNA & 0.13 & 0.34 & 0.00 & 1.00 \\
Viral Vector (replicating) & 0.09 & 0.29 & 0.00 & 1.00 \\
Viral Vector (non-replicating) & 0.13 & 0.33 & 0.00 & 1.00 \\
Virus Like Particle & 0.08 & 0.27 & 0.00 & 1.00 \\
Inactivated Virus & 0.08 & 0.27 & 0.00 & 1.00 \\
Other & 0.26 & 0.44 & 0.00 & 1.00 \\
\hline
\end{tabular}


Table A4: Descriptive statistics on potential COVID-19 sponsors $(n=1,773)$

\begin{tabular}{lcccc}
\hline & Mean & S.D. & Min & Max \\
\hline Nr of COVID-19 trials & 0.41 & 1.28 & 0.00 & 27.00 \\
Any COVID-19 trial & 0.20 & 0.40 & 0.00 & 1.00 \\
Sponsor size & 7.92 & 18.54 & 2.00 & 281.00 \\
$\begin{array}{l}\text { Prior experience with } \\
\text { respiratory diseases }\end{array}$ & 0.06 & 0.23 & 0.00 & 1.00 \\
Private sponsor & 0.46 & 0.50 & 0.00 & 1.00 \\
& & & & \\
Sponsor location & & & & \\
U.S. & 0.35 & 0.48 & 0.00 & 1.00 \\
Europe & 0.25 & 0.43 & 0.00 & 1.00 \\
China & 0.16 & 0.36 & 0.00 & 1.00 \\
ROW & 0.25 & 0.43 & 0.00 & 1.00 \\
\hline
\end{tabular}

Table A5: Descriptive statistics on COVID-19 trials $(\mathrm{n}=1,433)$

\begin{tabular}{lcccc}
\hline & Mean & S.D. & Min & Max \\
\hline Private sponsor & 0.31 & 0.46 & 0.00 & 1.00 \\
Sponsor has prior experience & 0.12 & 0.32 & 0.00 & 1.00 \\
with respiratory diseases & & & & \\
Sponsor conducted more than & 0.50 & 0.50 & 0.00 & 1.00 \\
50 trials from 2015 to 2019 & & & & \\
& & & & \\
Trial location & & & & \\
US & 0.32 & 0.47 & 0.00 & 1.00 \\
Europe & 0.23 & 0.42 & 0.00 & 1.00 \\
China & 0.05 & 0.22 & 0.00 & 1.00 \\
ROW & 0.40 & 0.49 & 0.00 & 1.00 \\
\hline
\end{tabular}




\section{Appendix 2: A Simple Model of Directed R\&D}

\section{Model}

\section{Overview}

This section builds on the model of Acemoglu and Linn (2004) to study the impact of market size on innovation, with a special focus on innovation directed towards COVID-19 innovation. The model makes three modifications to their model: (a) Disease-Specific Taxation: To take into account the feature that government's often pay for drugs on behalf of the citizens-especially that is needed by a large fraction of the population (e.g. vaccines) — we allow for disease-specific taxation, (b) Non-Monetary Incentives for Innovation: We consider the possibility that researchers may have non-monetary motivation (i.e. altruism motive or reputational incentives) to pursue R\&D, and (c) Economy-Wide Decreasing Returns: To capture the effect of limited supply of top researchers, we allow for economy-wide decreasing returns to scale to R\&D effort (instead of diseasespecific decreasing returns to scale as in the original model). Other than these three modifications, the setup of the model is identical to Acemoglu and Linn (2004), which we follow closely.

\section{Setup}

Consider a small open economy consisting of a set $I$ of infinitely lived individuals. Time is continuous $t \in[0, \infty)$. There are two types of goods in this economy. First, there is a basic good $y$, which can be used for consumption, for the production of other goods, or for research expenditure. Each individual $i$ has an exogenously given endowment $y_{i}(t)$ at time $t$. Second, there are $J$ drugs, $x_{1}, \ldots, x_{J}$, each with a potentially time-varying "quality," $q_{1}(t), \ldots, q_{J}(t)$. Each individual demands only one type of drug. Here the term drug is broadly used to refer to either vaccines, treatments, or therapeutics. We partition the set $I$ of individuals into $J$ disjoint groups, $G_{1}, \ldots, G_{J}$ with $G_{1} \cup G_{2} \cup \ldots \cup G_{J}=I$, such that if $i \in G_{j}$, then individual $i$ demands drug $j$. More specifically, if $i \in G_{j}$, then his preferences are given by:

$$
\int_{0}^{\infty} \exp (-r t)\left[\left(c_{i}(t)\right)^{1-\gamma}\left(q_{j}(t) x_{i j}(t)\right)^{\gamma}\right] d t
$$

where $r$ is the discount rate of the consumers and the interest rate faced by the economy, $\gamma \in(0,1), c_{i}(t)$ is the consumption of individual $i$ of the basic good at time $t$, and $x_{i j}(t)$ is the consumption of drug $j$. The Cobb-Douglas functional form and the assumption that each individual only consumes one type of drug are for simplicity as in Acemoglu and Linn (2004). Normalizing the price of the basic good to 1 in all periods, and 
denoting the price of drug $j$ at time $t$ by $p_{j}(t)$, the demand of individual $i \in I$ for $\operatorname{drug} j$ is $x_{i j}(t)=\gamma y_{i}(t) / p_{j}(t)$ if $i \in G_{j}$, and $x_{i j}(t)=0$ if $i \notin G_{j}$. Summing across individuals, total demand for drug $j$ is:

$$
X_{j}(t)=\frac{\gamma Y_{j}(t)}{p_{j}(t)}
$$

where $Y_{j}(t) \equiv \sum_{i \in G_{j}} y_{i}(t)$ is the total income of the group of individuals consuming drug $j$.

At a given point in time, there is one firm with the best-practice technology for producing each type of drug, and it can produce one unit of this drug with quality $q_{j}(t)$ using one unit of the basic good. If there is an innovation for drug line $j$ currently with quality $q_{j}(t)$, this leads to the discovery of a new drug of quality $\lambda q_{j}(t)$, with $\lambda>1$. It is assumed that any innovation can be sold to consumers immediately (and is under patent protection indefinitely). There is free entry into $R \& D$, and each firm has access to an $R \& D$ technology that generates a flow rate $j$ of innovation for every dollar spent for research on drug $j$. So if $R \& D$ expenditure at time $t$ is $z_{j}(t)$, the flow rate of innovation (and of entry of new drugs) for drug $j$ is:

$$
n_{j}(t)=\delta_{j} z_{j}(t) \phi(Z(t))
$$

Differences in $\delta_{j}>0$ introduce the possibility that technological progress is scientifically more difficult in some lines than others.

In addition, $\phi^{\prime}(Z) \leq 0$, and $Z$ represents the total innovation across all drugs, i.e. $Z(t)=\sum_{j \in 1, \ldots, J} z_{j}(t)$. This assumes that there is within-period decreasing returns to $R \& D$ effort with respect to total $R \& D$ effort in the economy. The intuition behind this assumption is there is a limited supply of top researchers, so when economywide R\&D effort gets scaled up, the average quality of R\&D effort may decline. (By contrast Acemoglu and Linn (2004) consider the case of disease-specific decreasing returns, i.e. with respect to $z_{j}$ and not overall $Z$ ). For simplicity, we assume that the economy-wide decreasing function takes the form of:

$$
\phi(Z(t))=\frac{R \& D \text { Capacity }}{\text { Total } R \& D}=\frac{C(t)}{Z(t)}
$$

with $C(t)>0$ for all t. The R\&D technology is directed in the sense that firms can devote their $\mathrm{R} \& \mathrm{D}$ to developing particular types of drugs. The demand curves in (5) have an elasticity equal to one, so an unconstrained monopolist would charge an arbitrarily high price. However, the firm with the best drug in line $j$ is competing with the next best drug in that line. An arbitrarily high price would allow the next best firm to capture the entire market. Therefore, the firm with the best drug sets a limit price to exclude the next best firm-i.e., to ensure that consumers prefer its product rather than the next best drug supplied at the lowest possible price (i.e., 
equal to marginal cost, which is 1). As in Acemoglu and Linn (2004), the limit price for all $j$ and $t$ is given by:

$$
p_{j}(t)=\lambda
$$

The flow profits of the firm with the best product of quality $q_{j}(t)$ in line $j$ at time $t$ is given by:

$$
\pi_{j}\left(q_{j}(t)\right)=\left(1-\tau_{j}\right)(\lambda-1) \gamma Y_{j}(t)
$$

Here $0 \leq \tau_{j}<1$ is a drug-specific tax rate imposed by the government, and $Y_{j}(t)$ corresponds to the market size (total sales) for drug $j$. Firms are forward-looking, and discount future profits at the rate $r$. The discounted value of profits for firms can be expressed by a standard dynamic programming recursion. $V_{j}\left(t \mid q_{j}\right)$, the value of a firm that owns the most advanced drug of quality $q_{j}$ in line $j$ at time $t$, is

$$
r V_{j}\left(t \mid q_{j}\right)-\dot{V}_{j}\left(t \mid q_{j}\right)=\pi_{j}\left(q_{j}(t)\right)-(1-\eta)\left[\delta_{j} z_{j}(t) \phi(Z(t)) V_{j}\left(t \mid q_{j}\right)\right]
$$

where $\pi_{j}\left(q_{j}(t)\right)$ is the flow profits, and $z_{j}(t)$ is $\mathrm{R} \& \mathrm{D}$ effort at time $t$ on this line by other firms. The value of owning the best technology in line $j, r V_{j}\left(t \mid q_{j}\right)$, is equal to the flow profits, $\pi_{j}\left(q_{j}(t)\right)$, plus the potential appreciation of the value, $\dot{V}_{j}\left(t \mid q_{j}\right)$, and takes into account that at the flow rate $n_{j}(t)=\delta_{j} z_{j}(t) \phi(Z(t))$ there will be an innovation, causing the current firm to lose its leading position and to make zero profits thereafter. The parameter $\eta \in[0,1]$ captures the non-monetary incentives and represents the degree to which the firm cares about bringing the innovation to market-independent of the possibility of its innovation being replaced by a new entrant at a future date. Another way to interpret the case of $\eta>0$ is that if a firm gains reputation value from being first to bring an innovation to the market then it would still derive non-monetary benefits from the innovation even after it has been replaced by new entrants. Note that the Acemoglu and Linn (2004) model has $\tau_{j}=0$ and $\eta=0$.

Free entry into R\&D to develop better quality drugs implies zero profits; i.e., for all $j$ and $t$ :

$$
\text { if } \quad z_{j}(t)>0, \text { then } \delta_{j} \phi(Z(t)) V_{j}\left(t \mid q_{j}\right)=1
$$

Meanwhile, if $z_{j}(t)=0$, then $\delta_{j} V_{j}\left(t \mid q_{j}\right) \leq 1$ and there will be no equilibrium R\&D for this drug.

\section{Equilibrium}

An equilibrium in this economy is given by sequences of prices $\left.p_{j}(t)\right|_{j=1, \ldots, J}$ that satisfy (8), consumer demands for drugs $\left.x_{i}(t)\right|_{i \in I}$ that satisfy (5) and R\&D levels $\left.z_{j}(t)\right|_{j=1, \ldots, J}$ that satisfy (11) with $V_{j}(\cdot)$ given by (10). 
Differentiating equation (11) with respect to time implies that $\dot{V}_{j}\left(t \mid q_{j}\right)=0$ for all $j$ and $t$, as long as $z_{j}(t)>0$. Substituting this equation and (11) into (10), and assuming $Y_{j}(t)=Y_{j}$ for all $t$ yields the levels of R\&D effort in the unique steady state equilibrium as:

$$
z_{j}^{S}=\max \left\{\frac{C \delta_{j}\left(1-\tau_{j}\right)(\lambda-1) \gamma Y_{j}-r \sum_{j \notin J} z_{j}^{S}}{(1-\eta) C \delta_{j}+r} ; 0\right\}
$$

Let drugs $J_{p o s}$ represent the subset of drugs for which $z_{j}(t)>0$. Then, the total research effort in the steady state is given by:

$$
Z^{S}=\frac{C \cdot \sum_{j \in J_{p o s}}\left(\left(1-\tau_{j}\right)(\lambda-1) \gamma Y_{j}\right)}{(1-\eta) C+r \sum_{j \in J_{p o s}}\left(\frac{1}{\delta_{j}}\right)}
$$

See appendix A.1 for derivations.

\section{Implications for Directed Innovation}

This model yields predictions about the direction of innovation in the pharmaceutical industry. These are presented below as six propositions to motivate empirical findings. Propositions 1 is consistent with the results of Acemoglu and Linn (2004), and do not depend on our extension of their model, while the other four propositions depend on our extensions of their model.

Proposition 1 characterizes the model's implication with respect to directed R\&D effort and market size.

Proposition 1 (Market Size Effect (with No Tax)). When tax does not depend on market size and firms are risk-neutral, a bigger market size leads to more directed $R \& D$ expenditure towards that drug by profitmaximizing firms, and this relationship is linear (i.e. there is no law of diminishing effort). That is, $\frac{d z_{j}^{S}}{d Y_{j}} \geq 0$, and $\frac{d^{2} z_{j}^{S}}{d Y_{j}^{2}}=0$

This result states that $\mathrm{R} \& \mathrm{D}$ effort is likely to be directed towards developing drugs for diseases with larger market size-and this relationship is linear in absence of taxes or risk aversion. The concept of market size $\left(Y_{j}\right)$ here corresponds to the total income of the group that demand drug $j$. Thus, the model predicts that R\&D effort will more likely be directed towards diseases that affect a larger population and/or diseases that affect higher-income populations (e.g. those that live in advanced economies). Thus, according to Proposition 1 when the market size of COVID-19 drugs becomes bigger, more R\&D effort will be directed towards COVID-19 as firms will find it more profitable to do so. What does this imply about the cross-effect on non-COVID-19 R\&D

effort, and on total R\&D effort across all diseases? The model's implications for aggregate R\&D effort and crowding out of other non-COVID R\&D is presented in Proposition 2. 
Proposition 2 (Effect of Market Size on Aggregate R\&D Effort and the Crowding Out Effect). An increase in $R \& D$ effort directed towards COVID crowds out $R \& D$ effort towards other diseases, but the size of crowding out is smaller when installed $R \& D$ capacity is bigger. That is, for all $j \neq C O V I D, \frac{d z_{j}^{S}}{d z_{C O V I D}} \leq 0$, and $\left|\frac{d^{2} z_{j}^{S}}{d z_{\operatorname{COVID}} d C}\right| \leq$ 0. At the same time, aggregate $R \& D$ effort increases, i.e. $\frac{d Z^{S}}{d z_{\text {CovID }}} \geq 0$.

As per Proposition 2, the model predicts that when the market size of COVID-19 drugs becomes larger it leads to a reduction in R\&D effort for non-COVID-19 diseases (depending on the magnitude of installed R\&D capacity), while at the same time it leads to an increase in total R\&D effort. This implies that under the model's assumptions, the crowding out effect of market size discussed in Proposition 1 is less than one-for-one.

Proposition 3 considers the role of non-monetary incentives in shaping R\&D effort.

Proposition 3 (Role of Non-Monetary Incentives). Firms with greater non-monetary incentives exert more $R \& D$ effort, i.e. $\frac{d z_{j}^{S}}{d \eta}>0$. Moreover, if $\frac{d z_{j}^{S}}{d Y_{j}} \geq 0$, then firms with greater non-monetary incentives exert more $R \& D$ effort for a drug with a larger market size, i.e. $\frac{d^{2} z_{j}^{S}}{d Y_{j} d \eta}>0$.

In our model, the non-monetary incentives act as an added motive to conduct R\&D effort. To see this, first note that in the classic creative destruction models upon which the model of Acemoglu and Linn (2004) is based, the possibility of having your innovation being replaced by another competitor works as a deterrent to innovation. In our model, however, firms that have greater non-monetary incentives (i.e. higher $\eta$ ) are less likely to internalize the deterring effect of being replaced by another firm (as they are value being first to bring an innovation to market beyond the monetary incentives). Thus, high $\eta$ firms are likely to exert more $\mathrm{R} \& \mathrm{D}$ effort. This same effect makes them more likely to exert R\&D effort towards drugs with a larger marker size, as they get the benefits of market size while being relatively less impacted by being replaced compared to low $\eta$ firms.

The first three propositions considered a case with no taxation. The next two propositions consider how disease-specific taxation impacts the relationship between market size and R\&D effort.

Proposition 4 (The Market Size Paradox and the Law of Diminishing Effort). If after-tax profits from a drug are subject to progressive taxation, i.e. $\frac{d \tau_{j}}{d Y_{j}}>0$ and $\frac{d^{2}\left(1-\tau_{j}\right) Y_{j}}{d Y_{j}^{2}}<0$, then directed $R \& D$ expenditure for drug $j$ is concave with respect to market size, i.e. $\frac{d^{2} z_{j}^{S}}{d Y_{j}^{2}}<0$.

Proposition 4 studies the case in which the ex-post taxation of a pharmaceutical firm's profits may depend on the market size. As discussed in the main text, we consider the case in which the pharmaceutical products may be subject to progressive taxation de facto due to political or social considerations. The notion of progressive 
taxation here relates to situation in which the tax rate rises with the market size and the after-tax profits are a concave function of the market size. A simple functional form for the tax rate that satisfies the progressive taxation assumption is: $\tau_{j}=1-\alpha Y_{j}^{-\beta}$ for some non-negative constants $\alpha, \beta$ with $\beta<1$. This proposition shows why this could be one reason why we observe a concave relationship between the R\&D effort directed towards development of drugs for a disease and its market size. Moreover, as discussed in proposition 5 below, when the convexity of taxation becomes relatively high, we can have a situation in which an increase in market size can lead to a decrease in R\&D effort. We see the results in Proposition 4 and 5 as one possible mechanism (among others) by which one may generate the law of diminishing effort in the model.

Proposition 5 (The Market Size Paradox and the Reversal Effect). If the elasticity of taxation with respect to market size exceeds the inverse tax ratio at some point, i.e. $\frac{d \ln \tau_{j}}{d \ln Y_{j}}>\frac{\left(1-\tau_{j}\right)}{\tau_{j}}$, then we the market size paradox can lead to reversal effects, such that an increase in market size reduces directed $R \& D$ expenditure towards drug j, i.e. $\frac{d z_{j}^{S}}{d Y_{j}}<0$.

The next section discusses how we map these propositions to our empirical propositions.

\section{Mapping the Model to Data}

The main predictions of the model relate to the $R \& D$ innovation in the pharmaceutical industry responds to (a) market size $\left(Y_{j}\right)$, (b) non-monetary incentives, and (c) disease-specific taxation regimes $\left(\tau_{j}\right)$. To test the predictions with respect to market size we rely on variation in the income-weighted death burden of different diseases. Thus, we interpret $j$ as a given disease (e.g. COVID-19, Malaria, etc.), and evaluate $Y_{j}$ by summing up the national death burden weighted by the GDP per capita of each country. Following Acemoglu and Linn (2004), we derive the estimation equation for Table 1, by considering equation (12) as $r \rightarrow 0$. To account for de facto progressive taxation we suppose $\tau_{j}=1-\alpha Y_{j}^{-\beta}$ for some non-negative constants $\alpha, \beta$ with $\beta<1$ (as in Proposition 4). Then, we can re-write equation (12) as:

$$
\ln z_{j}^{S}=\text { Constant }+\eta+(1-\beta) \ln Y_{j}
$$

where Constant $=\ln (\lambda-1)+\ln \gamma+\ln \alpha$ and we have used the $\log$ approximation $-\ln (1-\eta) \approx \eta$. That is, $\log$ R\&D effort is a function of the $\log$ market size $Y_{j}$, non-monetary incentives $\eta$, and a constant term. Here, the elasticity of $R \& D$ effort with respect to market size is given by $1-\beta$. This is the relationship we estimate in Table 1 . Note that the constant term is an increasing function of non-monetary incentives $\eta$, such that a greater presence of non-monetary incentives increases research effort. 


\section{Proofs and Derivations}

\section{A.1: Derivation of Steady State R\&D Effort}

Differentiating equation (11) with respect to time implies that $\dot{V}_{j}\left(t \mid q_{j}\right)=0$ for all $j$ and $t$, as long as $z_{j}(t)>0$. Substituting this equation and (11) into (10), and assuming $Y_{j}(t)=Y_{j}$ for all $t$ yields the levels of R\&D effort in the unique steady state equilibrium as:

$$
z_{j}^{S}=\max \left\{\frac{\left(1-\tau_{j}\right)(\lambda-1) \gamma Y_{j} \delta \phi\left(Z^{S}\right)-r}{\delta \phi\left(Z^{S}\right)(1-\eta)} ; 0\right\}
$$

Based on (4) we have $\phi\left(Z^{S}\right)=\frac{C}{Z^{S}}$, and $Z^{S}=\sum_{j \in 1, \ldots, J} z_{j}^{S}$. Substituting these into (14) above we get:

$$
z_{j}^{S}=\max \left\{\frac{C \delta_{j}\left(1-\tau_{j}\right)(\lambda-1) \gamma Y_{j}-r \sum_{j \notin J} z_{j}^{S}}{(1-\eta) C \delta_{j}+r} ; 0\right\}
$$

Let drugs $J_{\text {pos }}$ represent the subset of drugs for which $z_{j}(t)>0$. Substituting $Z^{S}=\sum_{j \in 1, \ldots, J} z_{j}^{S}$ in the equation for $\phi\left(Z^{S}\right)=\frac{C}{Z^{S}}$, and summing over all $j$ in (14) we can total research effort in steady state as:

$$
Z^{S}=\sum_{j \in 1, \ldots, J_{p o s}} z_{j}^{S}=\frac{C \cdot \sum_{j \in J_{p o s}}\left(\left(1-\tau_{j}\right)(\lambda-1) \gamma Y_{j}\right)}{(1-\eta) C+r \sum_{j \in J_{p o s}}\left(\frac{1}{\delta_{j}}\right)}
$$

\section{A.2: Proof of Propositions}

Proposition 1: The first proposition considers the case with $\frac{d \tau_{j}}{d Y_{j}}=0$. Under this case if $z_{j}^{S}>0$, taking the derivative in (15) we get:

$$
\frac{d z_{j}^{S}}{d Y_{j}}=\frac{C \delta_{j}\left(1-\tau_{j}\right)(\lambda-1) \gamma}{(1-\eta) C \delta_{j}+r}
$$

and the second derivative is zero: $\frac{d^{2} z_{j}^{S}}{d Y_{j}^{2}}=0$.

The first derivative is positive since by assumption, $\lambda>1, r \geq 0, C>0, \delta_{j}>0,0 \leq \tau_{j}<1, \eta \leq 1$. Thus, we have the result for Proposition 1: if $\frac{d \tau_{j}}{d Y_{j}}=0$ then $\frac{d z_{j}^{S}}{d Y_{j}} \geq 0$ and $\frac{d^{2} z_{j}^{S}}{d Y_{j}^{2}}=0$.

Proposition 2: For the second proposition consider the case with $z_{j}^{S}>0$. Then taking the derivative in (15) we get for all $j \neq C O V I D$ :

$$
\frac{d z_{j}^{S}}{d z_{C O V I D}}=-\frac{r}{(1-\eta) C \delta_{j}+r}<0
$$

which is negative under our parameter assumptions. Thus, we have the result presented in Proposition 2: for all $j \neq C O V I D, \frac{d z_{j}^{S}}{d z_{C O V I D}} \leq 0$. Also, the magnitude of crowding is smaller when the installed R\&D capacity 
$(C)$ is larger such that: and $\left|\frac{d^{2} z_{j}^{S}}{d z \operatorname{CoVID} d C}\right|=-r(1-\eta) \delta_{j}=\leq 0$.

In addition, taking derivative of (16) with respect to $z_{C O V I D}$ we get:

$$
\frac{d Z^{S}}{d z_{C O V I D}}=\frac{d Z^{S}}{d Y_{\text {COVID }}} \frac{d Y_{\text {COVID }}}{d z_{\text {COVID }}}=\frac{\left(1-\tau_{j}\right)(\lambda-1) \gamma C}{(1-\eta) C+r \sum_{j \in J_{p o s}}\left(\frac{1}{\delta_{j}}\right)}\left(\frac{d Y_{\text {COVID }}}{d z_{\text {COVID }}}\right)
$$

which under our assumptions and the result of Proposition 1 is positive. Thus, we have the result presented in Proposition 2: for all $\frac{d Z^{S}}{d z_{\text {COVID }}} \geq 0$.

Proposition 3: To derive the result for the third proposition we can take the derivative of $R \& D$ effort in (15) with respect to $\eta$ and the cross-derivative with respect to $\eta$ and market size $Y_{j}$ to get:

$$
\begin{aligned}
\frac{d z_{j}^{S}}{d \eta} & =\frac{C \delta_{j}\left[\left(1-\tau_{j}\right)(\lambda-1) \gamma Y_{j} C \delta_{j}-r \sum_{j \notin J} z_{j}^{S}\right]}{\left[(1-\eta) C \delta_{j}+r\right]^{2}} \\
\frac{d^{2} z_{j}^{S}}{d Y_{j} d \eta} & =\frac{C^{2} \delta_{j}^{2}\left(1-\tau_{j}\right)(\lambda-1) \gamma\left(1-\tau_{j}-Y_{j} \frac{d \tau_{j}}{d Y_{j}}\right)}{\left[(1-\eta) C \delta_{j}+r\right]^{2}}
\end{aligned}
$$

Thus, as represented in Proposition 3, under our parameter assumptions, $\frac{d z_{j}^{S}}{d \eta}>0$. And, $\frac{d^{2} z_{j}^{S}}{d Y_{j} d \eta}>0$ as long we do not have a paradox of market size effect, i.e. as long as $1-\tau_{j}-Y_{j} \frac{d \tau_{j}}{d Y_{j}}>0$ or equivalently as long as $\frac{d z_{j}^{S}}{d Y_{j}}>0$.

Proposition 4: The fourth proposition considers the case $\tau_{j}$ a function of $Y_{j}$ such that $\frac{d \tau_{j}}{d Y_{j}} \geq 0$ and $\left(1-\tau_{j}\right) Y_{j}$ is a concave function of $Y_{j}$. The second condition is equivalent to having: $2 \frac{d \tau_{j}}{d Y_{j}}+Y_{j} \frac{d^{2} \tau_{j}}{d Y_{j}^{2}}>0$. Then note that when $z_{j}>0$, taking the first and second derivatives of $z_{j}^{S}$ with respect to $Y_{j}$ in (15) we get:

$$
\begin{aligned}
\frac{d z_{j}^{S}}{d Y_{j}} & =\frac{C \delta_{j}\left(1-\tau_{j}\right)(\lambda-1) \gamma\left(1-\tau_{j}-Y_{j} \frac{d \tau_{j}}{d Y_{j}}\right)}{(1-\eta) C \delta_{j}+r} \\
\frac{d^{2} z_{j}^{S}}{d Y_{j}^{2}} & =-\frac{C \delta_{j}\left(1-\tau_{j}\right)(\lambda-1) \gamma\left(2 \frac{d \tau_{j}}{d Y_{j}}+Y_{j} \frac{d^{2} \tau_{j}}{d Y_{j}^{2}}\right)}{(1-\eta) C \delta_{j}+r}
\end{aligned}
$$

Under our assumptions then we get $\frac{d^{2} z_{j}^{S}}{d Y_{j}^{2}} \leq 0$, which is the result in Proposition 4 .

Proposition 5: The fifth proposition sets out the conditions under which $\frac{d z_{j}^{S}}{d Y_{j}}<0$. From the first derivative derived in the proof of proposition 4 , we can see this is the case when:

$$
1-\tau_{j}-Y_{j} \frac{d \tau_{j}}{d Y_{j}}<0
$$


This is equivalent to the condition $\frac{d \tau_{j}}{d Y_{j}}>\frac{1-\tau_{j}}{Y_{j}}$. Substituting $\frac{d \ln \tau_{j}}{d \ln Y_{j}}=\frac{Y_{j}}{\tau_{j}} \frac{d \tau_{j}}{d Y_{j}}$ we can re-write the condition as:

$$
\frac{d \ln \tau_{j}}{d \ln Y_{j}}>\frac{\left(1-\tau_{j}\right)}{\tau_{j}}
$$

which is the result in Proposition 5. 